\title{
A thermo-elasto-viscoplastic constitutive model for polymers
}

\author{
Joakim Johnsen ${ }^{\mathrm{a}, *}$, Arild Holm Clausen ${ }^{\mathrm{a}}$, Frode Grytten ${ }^{\mathrm{b}}$, Ahmed Benallal $^{\mathrm{c}}$, Odd Sture Hopperstad ${ }^{\mathrm{a}}$ \\ ${ }^{a}$ Structural Impact Laboratory (SIMLab), Department of Structural Engineering, NTNU, Norwegian University of Science and \\ Technology, NO-7491 Trondheim, Norway \\ ${ }^{b}$ SINTEF Industry, Department of Materials and Nanotechnology, PB 124 Blindern, NO-0314 Oslo, Norway \\ ${ }^{c}$ LMT, ENS Paris-Saclay/CNRS/Université Paris-Saclay, 61 Avenue du Président Wilson, Cachan Cedex, F 94235, France
}

\begin{abstract}
Tensile tests conducted at different temperatures and strain rates on a low density cross-linked polyethylene (XLPE) have shown that increasing the strain rate raises the yield stress in a similar manner as when the temperature is decreased. The locking stretch also increases as a function of the strain rate, but not to the same extent as by decreasing the temperature. The volumetric straining and self-heating of the specimens were also measured in the experimental campaign: at room temperature the material was close to incompressible, while at the lower temperatures it was found to be moderately compressible. At the lowest strain rate isothermal conditions was observed, while adiabatic heating was seen at the highest strain rate.

In this study, a thermo-elasto-viscoplastic model is developed for XLPE in an attempt to describe the combined effects of temperature and strain rate on the mechanical stress-strain response but also on the thermodynamical response. The proposed model consists of two parts. On one side, Part A models the thermoelastic and thermoviscoplastic response, and incorporates an elastic Hencky spring in series with two Ree-Eyring dashpots. The two Ree-Eyring dashpots represent the effects of the main $\alpha$ relaxation and the secondary $\beta$ relaxation processes on the plastic flow. Part $\mathrm{B}$, on the other side, consists of an eight chain spring capturing the entropic strain hardening due to alignment of the polymer chains during deformation.

The constitutive model was implemented in a nonlinear finite element (FE) code using a semi-implicit stress update algorithm combined with sub-stepping and a numerical scheme to calculate the consistent tangent operator. After calibration to available experimental data, FE simulations with the constitutive model are shown to successfully describe the stress-strain curves, the volumetric strain, the local strain rate and the self-heating observed in the tensile tests. In addition, the FE simulations adequately predict the global response of the tensile tests, such as the force-displacement curves and the deformed shape of the tensile specimen.
\end{abstract}

Keywords: Temperature, Constitutive model, Polyethylene, XLPE, Strain rate sensitivity, Self-heating 


\section{Introduction}

The use of polymers in structural applications has increased during the last decades. Some examples are shock absorbers in cars designed for pedestrian protection, thermal insulation of pipelines in the offshore oil industry and electrical insulation of high-voltage cables. The mechanical behaviour of polymers is complex and factors such as strain rate, temperature and stress triaxiality have a great impact on the structural behaviour of polymer components. Thus, it is a challenging task to obtain accurate numerical predictions of the mechanical response of polymeric materials under different loading scenarios. Prototype testing has therefore become a normal way to qualify materials and structural components for given applications in the industry. Qualifying materials in this manner is both costly and time consuming; thus there is a need for sufficiently accurate and easy-to-use material models. By using reliable material models, a limited set of experiments can be conducted for calibration purposes, and subsequently, numerical analyses of the structural component can be used either to optimize geometry or to investigate the effect of using different materials.

There is a number of available material models for polymers. Haward and Thackray [1] were the first to decouple the stress into one part where the elastic response was modelled by Hookean elasticity and a single Eyring dashpot [2] was employed to represent the inelastic flow, and a second part concerning entropic strain hardening using a Langevin spring derived from non-Gaussian chain statistics [3]. This model was extended to a three-dimensional (3D) formulation by Boyce et al. [4], who also incorporated strain softening and pressure sensitivity. Further development of the entropic strain hardening was done by Arruda et al. [5], resulting in the well-known eight chain model used in the current study. Regarding the flow process, Ree and Eyring [6] extended the original model by Eyring [2] to include several relaxation times, which in our work are restricted to two, namely the main $\alpha$ relaxation and the secondary $\beta$ relaxation [7, 8].

An important aspect regarding the Ree-Eyring flow process is that it does not include strain hardening. A common way of including strain hardening has been to introduce a backstress, see e.g. [1, 4, 9, 10]. A problem that may arise from this approach is that self-heating, due to the viscous flow, can be underestimated. This leads to difficulties when trying to describe thermal softening in polymers at elevated strain rates [11-13]. Another way of including strain hardening was proposed by Hoy and Robbins [14]. Using a multiplicative rate sensitivity formulation where the hardening modulus was scaled by the flow stress, they

\footnotetext{
${ }^{*}$ Corresponding author

Email address: joakim.johnsen@ntnu.no (Joakim Johnsen)
} 
obtained good results for the strain rates and temperatures covered in their study. However, investigating different polymers at strain rates yielding isothermal conditions, Govaert et al. [15] showed that the modelling approach of Hoy and Robbins [14] did not work in general. Instead they suggested to introduce a backstress in addition to viscous strain hardening, where the viscous strain hardening may either be modelled by stress-scaling of the hardening modulus [14], or by introducing a non-constant strain dependent activation volume in the Eyring model as proposed by Wendlandt et al. [16]. The latter approach is thoroughly evaluated by Senden et al. [17]. Their work shows the problematic behaviour in cyclic loading if the entire strain hardening is incorporated in the strain dependent activation volume (or strain dependent reference strain rate), namely that instead of continuing strain hardening when going from tension to compression, the model will predict strain softening since the activation volume will start to decrease when the loading direction is reversed. To avoid this unphysical behaviour, a portion of the strain hardening has to be modelled by an inelastic backstress.

The viscous behaviour contributes to self-heating in a material. In the studies performed by Adams and Farris [18] and Boyce et al. [19], it was found that about $50-80 \%$ of the total mechanical work was converted into heat in glassy polymers. On the other hand, studying high density polyethylene (HDPE), Hillmansen et al. [20, 21] observed that almost the entire mechanical work was converted into heat. A similar observation was also done by Johnsen et al. [11] on a crosslinked low density polyethylene (XLPE). Since heating of the polymer material will introduce thermal softening, it is evident that a correct prediction of heat generation during deformation is crucial in order for the constitutive model to capture the material behaviour over a range of strain rates. Consequently, taking into account thermomechanical coupling is important in this situation, and in particular accounting for heat conduction within the material and heat convection to the surroundings. There are many examples of thermomechanically coupled constitutive models. Arruda et al. [13] and Boyce et al. [19] combined an elastic Hookean response with non-Newtonian viscous flow and kinematic hardening based on the alignment of the polymer chains. Adopting a similar approach, Richeton et al. [22] presented a model able to span the glass transition temperature. More recent developments were made by Garcia-Gonzalez et al. [23] who extended the isothermal model proposed by Polanco-Loria et al. [24] to include thermomechanical coupling. This model combines an elastic NeoHookean response with rate-dependent yielding and plastic flow governed by the Raghava yield function [25] and kinematic hardening modelled by an eight chain spring. Another extension of the Polanco-Loria et al. [24] model was done by Ognedal et al. [26], who added isotropic hardening of the Raghava yield 
surface. Anand et al. [27] and Ames et al. [28] presented a thermomechanically coupled constitutive model describing the large deformation behaviour of amorphous polymers, including loading/unloading and torsion. In another study, Maurel-Pantel et al. [29] proposed a visco-hyperelastic constitutive model to capture large deformations and self-heating in a semi-crystalline polyamide 66. In the study by Srivastava et al. [30], the model presented by Anand et al. [27] was extended to span the glass transition temperature. The material model's ability to span the glass transition temperature is of course desirable, but it inevitably introduces additional parameters and adds complexity to the calibration procedure. Thus, we have chosen to limit our study to temperatures above the glass transition, namely the leathery region [8] between the glass transition and melting temperatures.

The thermomechanical behaviour of a cross-linked low density polyethylene (XLPE) material was studied experimentally in Johnsen et al. [11] using the experimental set-up described in Johnsen et al. [31]. Similar studies concerned with the effect of low temperatures on the mechanical behaviour have been performed, see e.g. Richeton et al. [32], Brown et al. [33], Serban et al. [34] and Bauwens-Crowet [35]. All of these studies revealed the same trends as observed by Johnsen et al. [11], namely that lowering the temperature increases the yield stress in a similar manner as an increase in strain rate, indicating that the yield stress may be determined from thermal activation theory [6, 36]. However, in these studies the strains were obtained by mechanical measurement techniques, as opposed to the local measurements made possible by digital image correlation (DIC) in Johnsen et al. [11]. Additionally, self-heating due to elevated strain rates was not reported.

In this study, based on the experimental investigation outlined above and described in the next section, we present a thermo-elasto-viscoplastic model to describe the mechanical behaviour of XLPE at different temperatures and strain rates. The proposed model has two parts: Part A consists of an elastic Hencky spring in series with two Ree-Eyring dashpots. The two Ree-Eyring dashpots model the effects of the main $\alpha$ relaxation and the secondary $\beta$ relaxation processes on the plastic flow. Part B consists of an entropic eight chain spring modelling strain hardening due to alignment of the polymer chains during deformation. The constitutive model is implemented in the commercial finite element (FE) program Abaqus/Standard as a UMAT subroutine. A semi-implicit stress update algorithm is combined with a sub-stepping procedure to ensure convergence. The consistent tangent operator is found by numerical differentiation as proposed by Miehe [37] and Sun et al. [38].

This paper is organized as follows: first, we briefly describe the material investigated here followed 

diameter $\times$ thickness). Material properties of the XLPE material is given in Table 1 . compared to the experimental findings allowing some concluding remarks to be drawn.

\section{Material, experimental set-up, methods and experimental results}

Table 1: Material properties for the XLPE material. All parameters are given for room temperature [11, 31].

Density, $\rho$ Specific heat capacity, $C_{\mathrm{p}} \quad$ Thermal conductivity, $k \quad$ Heat transfer coefficient to air, $h_{c}$

\begin{tabular}{cccc}
$\left(\mathrm{kg} / \mathrm{m}^{3}\right)$ & $(\mathrm{J} /(\mathrm{kg} \cdot \mathrm{K}))$ & $(\mathrm{W} /(\mathrm{m} \cdot \mathrm{K}))$ & $\left(\mathrm{W} /\left(\mathrm{m}^{2} \cdot \mathrm{K}\right)\right)$ \\
\hline 922 & 3546 & 0.56 & 21 \\
\hline
\end{tabular}

by a summary of the experimental set-up [31] along with the main experimental results obtained in [11]. Then the constitutive model is presented within a general thermodynamical framework including the heat equation used to calculate the temperature increase. This is followed by a brief outline of the numerical integration procedure and the calibration procedure. Finally, the results obtained from simulations are

In this study, we consider the material behaviour of a cross-linked low density polyethylene (XLPE) material. The material is produced by Borealis under the product name Borlink LS4201S [39] and was received from Nexans Norway as extruded high-voltage cable segments where the copper conductor had been removed. The dimensions of the cable segments were $128 \mathrm{~mm} \times 73 \mathrm{~mm} \times 22.5 \mathrm{~mm}$ (length $\times$

The experimental set-up consisted of a purpose-built transparent polycarbonate temperature chamber, where a thermocouple temperature sensor mounted close to the test specimen maintained the desired temperature by controlling the flow of liquid nitrogen into the chamber. In contrast to conventional temperature chambers with non-transparent walls, the polycarbonate chamber made it possible to monitor the test specimen using two digital cameras, enabling the calculation of the strains on two perpendicular surfaces using digital image correlation (DIC) - a necessity due to the slight transverse anisotropy of the XLPE material. It was also feasible to measure self-heating of the specimen with a thermal camera. A sketch of the experimental set-up is given in Figure 1.

Uniaxial tension and compression tests were performed at four temperatures $\left(T=-30{ }^{\circ} \mathrm{C}, T=-15\right.$ ${ }^{\circ} \mathrm{C}, T=0{ }^{\circ} \mathrm{C}$ and $T=25{ }^{\circ} \mathrm{C}$ ) and three different cross-head velocities: $v=0.04 \mathrm{~mm} / \mathrm{s}, v=0.4 \mathrm{~mm} / \mathrm{s}$ and $v=4.0 \mathrm{~mm} / \mathrm{s}$. Assuming that all deformation happens over the parallel section of the tensile specimen, these cross-head velocities correspond to initial nominal strain rates $\dot{e}$ of $0.01 \mathrm{~s}^{-1}, 0.1 \mathrm{~s}^{-1}$ and $1.0 \mathrm{~s}^{-1}$. All 


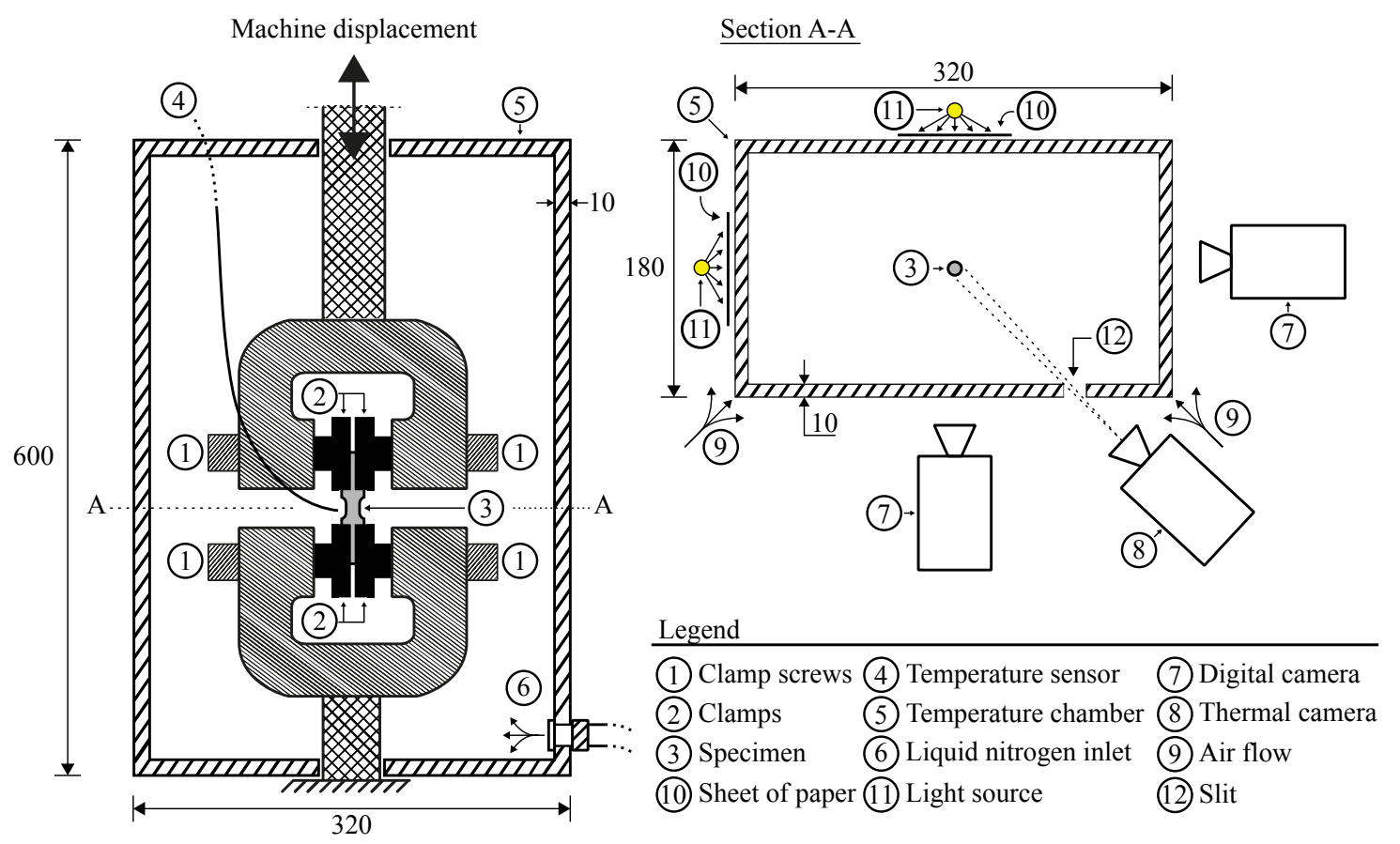

Figure 1: Illustration of the experimental set-up. All measures are in mm. For a detailed description see Johnsen et al. [11] 31]. cylindrical specimens used in these experiments.

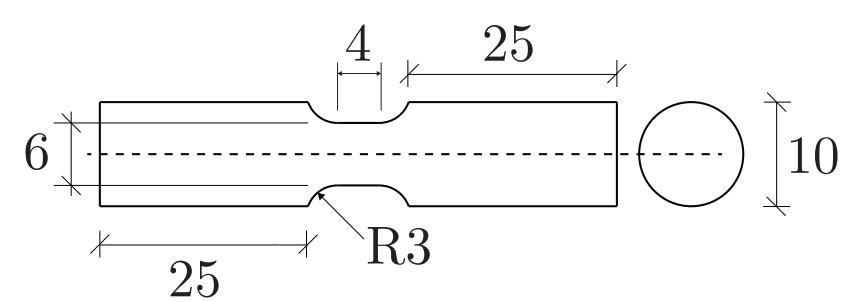

Figure 2: Illustration of the tensile test specimen. All measures are in $\mathrm{mm}$.

tests were performed in an Instron 5944 testing machine equipped with $2 \mathrm{kN}$ load cell. Figure 2 shows the

The transparency of the temperature chamber allowed us to monitor two perpendicular faces of the specimens during deformation using two digital cameras, an important feature due to the slight transverse anisotropy of the material [11]. Subsequent digital image correlation (DIC) analyses of the images were performed to obtain the longitudinal and transverse strains from the section of initial necking on both surfaces. Knowing the transverse strains in two perpendicular directions, the current cross-sectional area was calculated assuming an elliptical cross-section, enabling the calculation of the Cauchy stress as

$$
\sigma=\frac{F}{A}=\frac{F}{\pi r_{1} r_{2}}=\frac{F}{\pi r_{0}^{2} \lambda_{1} \lambda_{2}}
$$


where $r_{1}$ and $r_{2}$ are the radii recorded by each digital camera, $\lambda_{i}=r_{i} / r_{0}$ (for $i=1,2$ ) are the corresponding transverse stretches with $r_{0}$ equal to the initial radius of $3 \mathrm{~mm}$, and $F$ is the global force measured by the testing machine. Furthermore, the volumetric strain $\varepsilon_{\mathrm{V}}$ is found by summation of the three principal strain components, i.e.,

$$
\varepsilon_{\mathrm{V}}=\varepsilon_{\mathrm{L}}+\varepsilon_{1}+\varepsilon_{2}
$$

where $\varepsilon_{\mathrm{L}}$ is the longitudinal logarithmic strain and $\varepsilon_{i}=\ln \left(\lambda_{i}\right)$ are the transverse logarithmic strains.

In addition to the two digital cameras used to obtain the strains, an infrared thermal camera was employed to measure the self-heating of the material during the tensile experiments. A slit was added in the front window of the temperature chamber to obtain a free line-of-sight between the camera and the tensile specimen. The thermal camera operated down to a temperature of $-20^{\circ} \mathrm{C}$. To ensure that the correct temperature was maintained during the experiments, a thermocouple temperature sensor was used to control the flow of liquid nitrogen into the temperature chamber. All specimens were thermally conditioned for a minimum of 30 minutes inside the temperature chamber prior to testing. To avoid icing on the outside of the chamber, and consequently obstruction of the digital camera imaging, fans were used to blow air continuously over the chamber walls.

A condensed illustration of the local stress-strain behaviour reported in [11] is given in Figure 3. It appears that temperature-time equivalence applies for the XLPE material, namely that a decrease in temperature has a similar impact on Young's modulus and the flow stress as an increase in strain rate. Using two Ree-Eyring [6] dashpots, Johnsen et al. [11] successfully described the flow stress as a function of both temperature and strain rate, while they used a phenomenological expression similar to that proposed by Arruda et al. [13] to describe the temperature dependence of Young's modulus. It is also noted from Figure 3 that the locking stretch, defined as the stretch where an abrupt change in strain hardening occurs, increases with increasing strain rate, and decreases slightly with decreasing temperature. This phenomenon is believed to be caused by increased chain mobility due to self-heating at elevated strain rates, and decreased chain mobility at lower temperatures, respectively. The material was also found to be close to incompressible at room temperature, while it is compressible at the three lower temperatures. In terms of self-heating, it was shown in [11] that the lowest strain rate $\left(\dot{e}=0.01 \mathrm{~s}^{-1}\right)$ gave close to isothermal conditions. At the intermediate strain rate $\left(\dot{e}=0.1 \mathrm{~s}^{-1}\right)$ self-heating was observed, but due to the duration of the test, heat conduction inside the material and heat convection to the surroundings caused the temperature to decrease at the end of the experiment. For the tests performed at the highest strain rate $\left(\dot{e}=1.0 \mathrm{~s}^{-1}\right)$, close to adiabatic conditions 


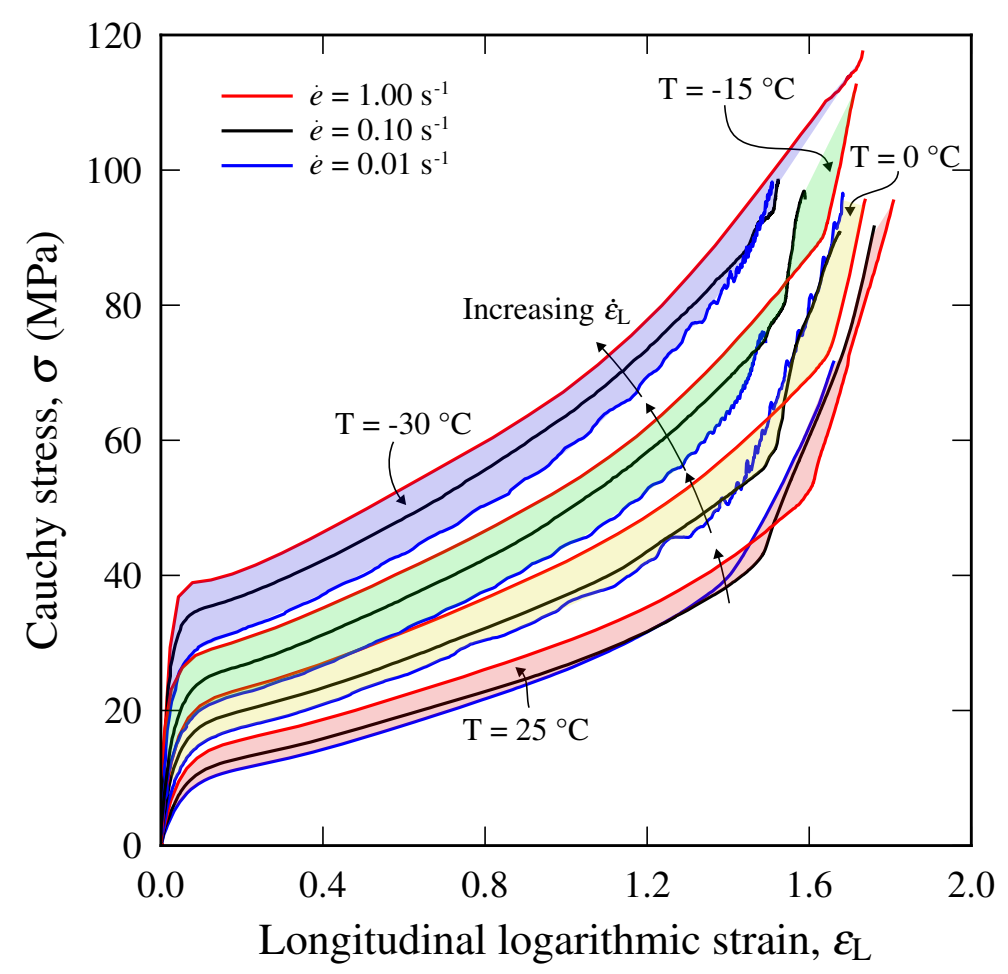

Figure 3: Condensed version of all stress-strain curves from experiments showing how the material behaviour is affected by changing the temperature and the strain rate. Adapted from Johnsen et al. [11].

were met, resulting in a temperature increase in the material between $20{ }^{\circ} \mathrm{C}$ and $35^{\circ} \mathrm{C}$. Further, uniaxial compression tests revealed that the yield stress is similar in tension and compression. The test results from [11] will be shown in full together with predictions from the numerical simulations in Section 6 .

For a more detailed presentation and discussion of the experimental set-up, the methods used to extract local stress-strain data and self-heating from experiments, and the experimental results, see Johnsen et al. [11, 31].

\section{Constitutive model}

In this section we present the thermo-elasto-viscoplastic model proposed to describe the thermomechanical behaviour observed in the experiments on the XLPE material. In addition to the features addressed in Figure 3, the model also aims at capturing the volumetric response and self-heating. The model has been implemented in the implicit framework provided by Abaqus/Standard as a user subroutine (UMAT). 


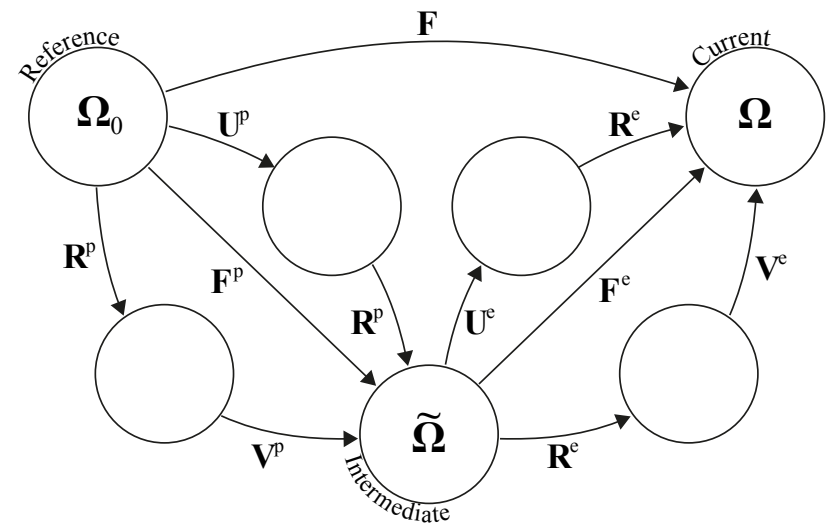

(a)

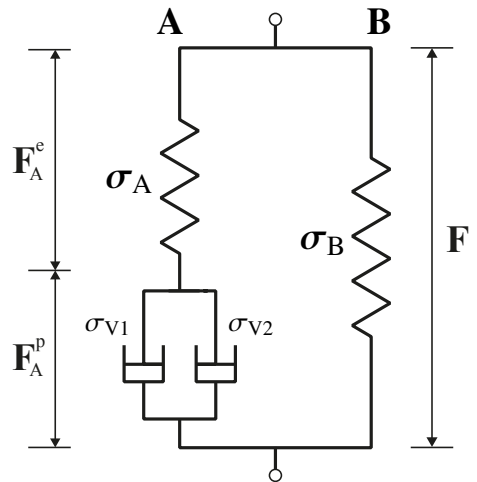

(b)

Figure 4: Large deformations kinematics using a multiplicative split of the deformation gradient, $\mathbf{F}$, is shown in (a), and (b) shows the rheological model.

Polar decomposition of the elastic and plastic parts of the deformation gradient of Part A yields

$$
\begin{aligned}
& \mathbf{F}_{\mathrm{A}}^{\mathrm{e}}=\mathbf{V}_{\mathrm{A}}^{\mathrm{e}} \mathbf{R}_{\mathrm{A}}^{\mathrm{e}}=\mathbf{R}_{\mathrm{A}}^{\mathrm{e}} \mathbf{U}_{\mathrm{A}}^{\mathrm{e}} \\
& \mathbf{F}_{\mathrm{A}}^{\mathrm{p}}=\mathbf{V}_{\mathrm{A}}^{\mathrm{p}} \mathbf{R}_{\mathrm{A}}^{\mathrm{p}}=\mathbf{R}_{\mathrm{A}}^{\mathrm{p}} \mathbf{U}_{\mathrm{A}}^{\mathrm{p}}
\end{aligned}
$$

where subscripts A and B denote Parts A and B of the rheological model, respectively. 
where $\mathbf{R}$ is the rotation tensor, $\mathbf{U}$ and $\mathbf{V}$ are the right and left stretch tensors, respectively, and superscripts e and p denote the elastic and plastic parts. The isochoric deformation gradient tensor $\overline{\mathbf{F}}$ is defined by

$$
\overline{\mathbf{F}}=J^{-1 / 3} \mathbf{F}
$$

where $J=\operatorname{det}(\mathbf{F})$ is the Jacobian determinant, thus implying that $\operatorname{det}(\overline{\mathbf{F}})=1$. The isochoric left CauchyGreen deformation tensor $\overline{\mathbf{B}}$ and the isochoric left stretch tensor $\overline{\mathbf{V}}$ are defined as

$$
\begin{aligned}
& \overline{\mathbf{B}}=\overline{\mathbf{F}} \overline{\mathbf{F}}^{T}=J^{-2 / 3} \mathbf{F} \mathbf{F}^{T}=J^{-2 / 3} \mathbf{B} \\
& \overline{\mathbf{V}}=\sqrt{\overline{\mathbf{B}}}=J^{-1 / 3} \sqrt{\mathbf{B}}=J^{-1 / 3} \mathbf{V}
\end{aligned}
$$

where $\mathbf{B}=\mathbf{F F}^{T}$ is the left Cauchy-Green deformation tensor. Throughout this study the plastic deformation is assumed to be isochoric, i.e., $J_{\mathrm{A}}^{\mathrm{p}}=1$ and thus $J_{\mathrm{A}}^{\mathrm{e}}=J$ since the decomposition of the Jacobian determinant $\operatorname{reads} J=\operatorname{det}(\mathbf{F})=\operatorname{det}\left(\mathbf{F}_{\mathrm{A}}^{\mathrm{e}}\right) \operatorname{det}\left(\mathbf{F}_{\mathrm{A}}^{\mathrm{p}}\right)=J_{\mathrm{A}}^{\mathrm{e}} J_{\mathrm{A}}^{\mathrm{p}}$. With respect to the elastic and plastic parts of the deformation gradient tensor, we then obtain the following relations:

$$
\begin{gathered}
\overline{\mathbf{F}}_{\mathrm{A}}^{\mathrm{e}}=J^{-1 / 3} \mathbf{F}_{\mathrm{A}}^{\mathrm{e}}, \quad \overline{\mathbf{B}}_{\mathrm{A}}^{\mathrm{e}}=\overline{\mathbf{F}}_{\mathrm{A}}^{\mathrm{e}}\left(\overline{\mathbf{F}}_{\mathrm{A}}^{\mathrm{e}}\right)^{T}=J^{-2 / 3} \mathbf{B}_{\mathrm{A}}^{\mathrm{e}}, \quad \overline{\mathbf{V}}_{\mathrm{A}}^{\mathrm{e}}=J^{-1 / 3} \mathbf{V}_{\mathrm{A}}^{\mathrm{e}} \\
\overline{\mathbf{F}}_{\mathrm{A}}^{\mathrm{p}}=\mathbf{F}_{\mathrm{A}}^{\mathrm{p}}, \quad \overline{\mathbf{B}}_{\mathrm{A}}^{\mathrm{p}}=\mathbf{F}_{\mathrm{A}}^{\mathrm{p}}\left(\mathbf{F}_{\mathrm{A}}^{\mathrm{p}}\right)^{T}=\mathbf{B}_{\mathrm{A}}^{\mathrm{p}}, \quad \overline{\mathbf{V}}_{\mathrm{A}}^{\mathrm{p}}=\mathbf{V}_{\mathrm{A}}^{\mathrm{p}}
\end{gathered}
$$

According to the rheological model in Figure 4b, the free energy is decomposed as follows

$$
\psi=\psi_{\mathrm{A}}+\psi_{\mathrm{B}}
$$

where $\psi_{\mathrm{A}}$ and $\psi_{\mathrm{B}}$ are the free energies of Parts $\mathrm{A}$ and $\mathrm{B}$, respectively. Note that the free energy function is here defined per unit reference mass. In the same manner, the Cauchy stress tensor is decomposed as

$$
\sigma=\sigma_{\mathrm{A}}+\sigma_{\mathrm{B}}
$$

where $\sigma_{\mathrm{A}}$ and $\sigma_{\mathrm{B}}$ are the Cauchy stress tensors acting in Parts A and B of the rheological model.

\subsubsection{Part A - Intermolecular}

Both the elastic and plastic responses of Part A are taken to be isochoric. The elastic response is defined by the Hencky free energy [41], i.e.,

$$
\rho_{0} \psi_{\mathrm{A}}=\mu_{\mathrm{A}}(\theta) \operatorname{tr}\left[\left(\ln \left(\overline{\mathbf{V}}_{\mathrm{A}}^{\mathrm{e}}\right)\right)^{2}\right]
$$


where $\rho_{0}$ is the initial density of the material and $\theta$ is the absolute temperature. The shear modulus of the elastic spring is temperature dependent through the following expression

$$
\mu_{\mathrm{A}}(\theta)=\mu_{\mathrm{A}, \operatorname{ref}} \exp \left[-a_{\mathrm{A}}\left(\theta-\theta_{\text {ref }}\right)\right]
$$

where $\theta_{\text {ref }}$ is a reference temperature, $\mu_{\mathrm{A}, \mathrm{ref}}$ is the shear modulus at the reference temperature, and $a_{\mathrm{A}}$ is a parameter governing the temperature sensitivity.

The Kirchhoff stress tensor $\tau_{\mathrm{A}}$ is obtained from the free energy function in Equation (14) as [42]

$$
\tau_{\mathrm{A}}=2 \rho_{0} \frac{\partial \psi_{\mathrm{A}}}{\partial \mathbf{B}_{\mathrm{A}}^{\mathrm{e}}} \mathbf{B}_{\mathrm{A}}^{\mathrm{e}}
$$

which after some algebra leads to [41]

$$
\tau_{\mathrm{A}}=2 \mu_{\mathrm{A}}(\theta) \ln \left(\overline{\mathbf{V}}_{\mathrm{A}}^{\mathrm{e}}\right)
$$

The Cauchy stress tensor $\sigma_{\mathrm{A}}$ is then given as

$$
\sigma_{\mathrm{A}}=\frac{1}{J} \tau_{\mathrm{A}}
$$

Now we focus on the thermoviscoplastic part of the constitutive model. Since the yield stress in tension and compression was found to be approximately the same [11], the pressure-insensitive von Mises equivalent stress is used

$$
\sigma_{\mathrm{D}}^{\mathrm{vm}}=\sqrt{\frac{3}{2} \sigma_{\mathrm{D}}^{\prime}: \sigma_{\mathrm{D}}^{\prime}}
$$

where $\sigma_{\mathrm{D}}^{\prime}=\sigma_{\mathrm{D}}-\frac{1}{3} \operatorname{tr}\left(\sigma_{\mathrm{D}}\right) \mathbf{1}$ is the deviatoric part of the driving stress $\sigma_{\mathrm{D}}=\sigma_{\mathrm{A}}$. From the rheological model (Figure $4 \mathrm{~b}$ ) it is evident that the equivalent driving stress must be balanced by the viscous stress associated with the Ree-Eyring [6] dashpots. Thus, assuming that the contribution from each dashpot is additive [7], we obtain

$$
\sigma_{\mathrm{V}}=\sigma_{\mathrm{V} 1}+\sigma_{\mathrm{V} 2}=\sum_{x=\alpha, \beta} \frac{k_{B} \theta}{V_{x}} \operatorname{arsinh}\left(\frac{\dot{p}}{\dot{p}_{0, x}^{*}} \exp \left[\frac{\Delta H_{x}}{R \theta}\right]\right)=\sigma_{\mathrm{D}}^{\mathrm{vm}}
$$

where $\alpha$ and $\beta$ denote the contributions from the main and secondary relaxation processes, respectively, $k_{B}$ is Boltzmann's constant, $V_{x}$ is the activation volume, $\dot{p}$ is the equivalent plastic strain rate, $\Delta H_{x}$ is the activation enthalpy, and $R$ is the universal gas constant. Further, $\dot{p}_{0, x}^{*}$ is the deformation dependent reference equivalent plastic strain rates given by

$$
\dot{p}_{0, x}^{*}=\dot{p}_{0, x} \exp \left(-\sqrt{\frac{2}{3}} b_{x}\left\|\ln \left(\mathbf{V}^{\mathrm{p}}\right)\right\|_{2}\right) \quad \text { for } \quad x=\alpha, \beta
$$


where $\dot{p}_{0, x}$ are the initial values of $\dot{p}_{0, x}^{*}, b_{\alpha}$ and $b_{\beta}$ are the parameters governing the deformation dependence, and $\left\|\ln \left(\mathbf{V}^{\mathrm{p}}\right)\right\|_{2}$ is the Frobenius norm of the Hencky strain tensor.

The velocity gradient $\mathbf{L}_{\mathrm{A}}$ and its decompositions are given by

$$
\begin{gathered}
\mathbf{L}_{\mathrm{A}}=\dot{\mathbf{F}}_{\mathrm{A}} \mathbf{F}_{\mathrm{A}}^{-1}=\left[\dot{\mathbf{F}}_{\mathrm{A}}^{\mathrm{e}} \mathbf{F}_{\mathrm{A}}^{\mathrm{p}}+\mathbf{F}_{\mathrm{A}}^{\mathrm{e}} \dot{\mathbf{F}}_{\mathrm{A}}^{\mathrm{p}}\right]\left(\mathbf{F}_{\mathrm{A}}^{\mathrm{p}}\right)^{-1}\left(\mathbf{F}_{\mathrm{A}}^{\mathrm{e}}\right)^{-1} \\
\mathbf{L}_{\mathrm{A}}=\dot{\mathbf{F}}_{\mathrm{A}}^{\mathrm{e}}\left(\mathbf{F}_{\mathrm{A}}^{\mathrm{e}}\right)^{-1}+\mathbf{F}_{\mathrm{A}}^{\mathrm{e}} \dot{\mathbf{F}}_{\mathrm{A}}^{\mathrm{p}} \mathbf{F}_{\mathrm{A}}^{-1}=\mathbf{L}_{\mathrm{A}}^{\mathrm{e}}+\mathbf{L}_{\mathrm{A}}^{\mathrm{p}} \\
\mathbf{L}_{\mathrm{A}}=\mathbf{D}_{\mathrm{A}}^{\mathrm{e}}+\mathbf{W}_{\mathrm{A}}^{\mathrm{e}}+\mathbf{D}_{\mathrm{A}}^{\mathrm{p}}+\mathbf{W}_{\mathrm{A}}^{\mathrm{p}}
\end{gathered}
$$

where $\mathbf{D}$ and $\mathbf{W}$ are in turn the rate-of-deformation tensor and the spin tensor. Due to isotropy, the plastic velocity gradient is taken to be irrotational [19, 43], i.e., the plastic spin tensor is equal to zero, $\mathbf{W}_{\mathrm{A}}^{\mathrm{p}}=\mathbf{0}$. The plastic rate-of-deformation tensor is given by the flow rule as

$$
\mathbf{D}_{\mathrm{A}}^{\mathrm{p}}=\mathbf{L}_{\mathrm{A}}^{\mathrm{p}}=\dot{\lambda} \frac{\partial g\left(\sigma_{\mathrm{D}}\right)}{\partial \sigma_{\mathrm{D}}}
$$

where $\dot{\lambda}$ is a plastic multiplier and $g\left(\sigma_{\mathrm{D}}\right)$ is the plastic potential. Assuming that the plastic flow is isochoric, the plastic potential is taken as

$$
g\left(\sigma_{\mathrm{D}}\right)=\sqrt{\frac{3}{2} \sigma_{\mathrm{D}}^{\prime}: \sigma_{\mathrm{D}}^{\prime}}=\sigma_{\mathrm{D}}^{\mathrm{vm}} \geq 0
$$

where the direction of plastic flow $\mathbf{N}$ is obtained from the gradient of the plastic potential,

$$
\mathbf{N}=\frac{\partial g\left(\sigma_{\mathrm{D}}\right)}{\partial \sigma_{\mathrm{D}}}=\frac{3}{2} \frac{\sigma_{\mathrm{D}}^{\prime}}{g\left(\sigma_{\mathrm{D}}\right)}
$$

Equivalence in terms of plastic power yields the relation between the equivalent plastic strain rate, $\dot{p}$, and the plastic multiplier, $\dot{\lambda}$, viz.

$$
\sigma_{\mathrm{D}}^{\mathrm{vm}} \dot{p}=\sigma_{\mathrm{D}}: \mathbf{D}_{\mathrm{A}}^{\mathrm{p}} \Rightarrow \dot{p}=\dot{\lambda}
$$

Combining Equations (23) and (25) and inserting $\dot{\lambda}=\dot{p}$, we obtain the expression for the evolution of the plastic deformation gradient, i.e.,

$$
\dot{\mathbf{F}}_{\mathrm{A}}^{\mathrm{p}}=\dot{p}\left(\mathbf{F}_{\mathrm{A}}^{\mathrm{e}}\right)^{-1} \frac{\partial g\left(\sigma_{\mathrm{D}}\right)}{\partial \sigma_{\mathrm{D}}} \mathbf{F}_{\mathrm{A}}
$$

\subsubsection{Part B - Orientational hardening}

The orientational hardening of the material due to the alignment of the polymer chains is captured by the eight chain model [5]. Following Miehe [44] we define a modified entropic free energy function, viz.

$$
\rho_{0} \psi_{\mathrm{B}}=\frac{\kappa(\theta)}{2}(\ln (J))^{2}-3 \kappa(\theta) \alpha \ln (J)\left(\theta-\theta_{0}\right)+T(\theta)+\mu_{\mathrm{B}}(\theta) \lambda_{\text {lock }}^{2}\left[\left(\frac{\bar{\lambda}_{\mathrm{c}}}{\lambda_{\text {lock }}}\right) \beta+\ln \left(\frac{\beta}{\sinh \beta}\right)\right]
$$


The shear modulus of Part B is interpreted as a rubbery modulus, i.e.,

$$
\mu_{\mathrm{B}}(\theta)=n k_{B} \theta=\mu_{\mathrm{B}, \mathrm{ref}} \frac{\theta}{\theta_{\mathrm{ref}}}
$$

where $n$ is the chain density, $k_{B}$ is Boltzmann's constant, and $\mu_{\mathrm{B} \text {,ref }}$ is the shear modulus at the reference temperature. In this study the reference temperature is set equal to $298.15 \mathrm{~K}$, while the initial temperature is equal to the temperatures at which the experiments were conducted. The temperature dependent bulk modulus $\kappa(\theta)$ is found by assuming that Poisson's ratio $v$ is constant, viz.

$$
\kappa(\theta)=\frac{2 \mu_{\mathrm{B}}(\theta)(1+v)}{3(1-2 v)}
$$

The linear thermal expansion coefficient $\alpha$ is assumed to be independent of temperature. Further, $\lambda_{\text {lock }}$ is the locking stretch, $\bar{\lambda}_{\mathrm{c}}=\sqrt{\operatorname{tr}(\overline{\mathbf{B}}) / 3}$ is an average chain stretch, and

$$
\beta=\mathcal{L}^{-1}\left(\frac{\bar{\lambda}_{\mathrm{c}}}{\lambda_{\text {lock }}}\right)
$$

where $\mathcal{L}^{-1}$ is the inverse Langevin function $(\mathcal{L}(x)=1 / x-\operatorname{coth} x)$ approximated by the formula proposed by Jedynak [45]:

$$
\mathcal{L}^{-1}(x) \approx x \frac{3-2.6 x+0.7 x^{2}}{(1-x)(1+0.1 x)}
$$

The purely thermal contribution to the free energy, which, assuming that the specific heat capacity, $C_{\mathrm{p}}$, is constant, is given as [44, 46]

$$
T(\theta)=C_{\mathrm{p}}\left[\left(\theta-\theta_{0}\right)-\theta \ln \left(\frac{\theta}{\theta_{0}}\right)\right]
$$

where $\theta_{0}$ is the initial absolute temperature.

The Kirchhoff stress tensor, $\tau_{\mathrm{B}}$, is found after some algebra as [46]

$$
\boldsymbol{\tau}_{\mathrm{B}}=2 \rho_{0} \frac{\partial \psi_{\mathrm{B}}}{\partial \mathbf{B}} \mathbf{B}=\frac{\mu_{\mathrm{B}}(\theta) \lambda_{\text {lock }}}{3 \bar{\lambda}_{\mathrm{c}}} \mathcal{L}^{-1}\left(\frac{\bar{\lambda}_{\mathrm{c}}}{\lambda_{\text {lock }}}\right) \overline{\mathbf{B}}^{\prime}+\kappa(\theta) \ln (J) \mathbf{1}-3 \kappa(\theta) \alpha\left(\theta-\theta_{0}\right) \mathbf{1}
$$

with $\overline{\mathbf{B}}^{\prime}=\overline{\mathbf{B}}-\frac{1}{3} \operatorname{tr}(\overline{\mathbf{B}}) \mathbf{1}$ being the deviatoric part of $\overline{\mathbf{B}}$, and the Cauchy stress reads as

$$
\sigma_{\mathrm{B}}=\frac{1}{J} \tau_{\mathrm{B}}
$$

\subsubsection{Self-heating and dissipation}

The internal energy $u$, defined per unit reference mass, is given in terms of the free energy $\psi$ and the entropy $s \equiv-\partial \psi / \partial \theta$ as

$$
u=\psi+\theta s
$$


Local energy balance is expressed as

$$
\rho_{0} \dot{u}=\boldsymbol{\tau}: \mathbf{D}+r-\operatorname{div}(\mathbf{q})
$$

where $r$ is external heat sources and $\mathbf{q}$ is the heat flux. The deformation power per unit reference volume is decomposed according to

$$
\tau: \mathbf{D}=\tau_{\mathrm{A}}:\left(\mathbf{D}_{\mathrm{A}}^{\mathrm{e}}+\mathbf{D}_{\mathrm{A}}^{\mathrm{p}}\right)+\tau_{\mathrm{B}}: \mathbf{D}=\tau_{\mathrm{A}}: \mathbf{D}_{\mathrm{A}}^{\mathrm{e}}+\tau_{\mathrm{D}}: \mathbf{D}_{\mathrm{A}}^{\mathrm{p}}+\tau_{\mathrm{B}}: \mathbf{D}
$$

where $\tau_{\mathrm{D}}=J \sigma_{\mathrm{D}}$, and only the deformation power in the two dashpots contributes to the intrinsic dissipation. After some calculations, the rates of change of the free energy and the entropy are obtained as [44]

$$
\begin{gathered}
\rho_{0} \dot{\psi}=\tau_{\mathrm{A}}: \mathbf{D}_{\mathrm{A}}^{\mathrm{e}}+\tau_{\mathrm{B}}: \mathbf{D}-\rho_{0} \dot{\theta} s \\
\rho_{0} \theta \dot{s}=-\theta \frac{\partial \tau_{\mathrm{A}}}{\partial \theta}: \mathbf{D}_{\mathrm{A}}^{\mathrm{e}}-\theta \frac{\partial \tau_{\mathrm{B}}}{\partial \theta}: \mathbf{D}+\rho_{0} C_{\mathrm{p}} \dot{\theta}
\end{gathered}
$$

where the specific heat capacity is defined as $C_{\mathrm{p}}=\theta \frac{\partial s}{\partial \theta}$ and

$$
\begin{gathered}
\frac{\partial \boldsymbol{\tau}_{\mathrm{A}}}{\partial \theta}=-2 a_{\mathrm{A}} \mu_{\mathrm{A}}(\theta) \ln \left(\overline{\mathbf{V}}_{\mathrm{A}}^{\mathrm{e}}\right)=-a_{\mathrm{A}} \boldsymbol{\tau}_{\mathrm{A}} \\
\theta \frac{\partial \boldsymbol{\tau}_{\mathrm{B}}}{\partial \theta}=\boldsymbol{\tau}_{\mathrm{B}}-3 \kappa(\theta) \alpha \theta \mathbf{1}
\end{gathered}
$$

The dissipation inequality may be stated as [42]

$$
\mathcal{D} \equiv-\rho_{0}(\dot{\psi}+s \dot{\theta})+\tau: \mathbf{D}-\frac{\mathbf{q}}{\theta} \cdot \frac{\partial \theta}{\partial \mathbf{x}} \geq 0
$$

where $\mathbf{x}$ is the position vector in the current configuration. Inserting Equations (40) and (41) yields

$$
\mathcal{D}=\tau_{\mathrm{D}}: \mathbf{D}_{\mathrm{A}}^{\mathrm{p}}-\frac{\mathbf{q}}{\theta} \cdot \frac{\partial \theta}{\partial \mathbf{x}} \geq 0
$$

The first term represents the intrinsic dissipation and is non-negative by the flow rule. The last term is the dissipation due to heat conduction and is made non-negative by adopting Fourier's law: $\mathbf{q}=-k \frac{\partial \theta}{\partial \mathbf{x}}$, where the conductivity $k$ is positive.

The heat equation is obtained by combining Equations (38) to (44), and the result comes out as

$$
\rho_{0} C_{\mathrm{p}} \dot{\theta}=\boldsymbol{\tau}_{\mathrm{D}}: \mathbf{D}_{\mathrm{A}}^{\mathrm{p}}+\boldsymbol{\tau}_{\mathrm{B}}: \mathbf{D}-\theta\left[a_{\mathrm{A}} \boldsymbol{\tau}_{\mathrm{A}}: \mathbf{D}_{\mathrm{A}}^{\mathrm{e}}+3 \kappa(\theta) \alpha \operatorname{tr}(\mathbf{D})\right]+r-\operatorname{div}(\mathbf{q})
$$

By solving for the temperature rate, the heat equation is used to calculate the self-heating of the material at elevated strain rates. 


\subsection{Numerical integration}

The governing equations of Part A of the constitutive model are compiled in Box 1 .

Box 1: Governing equations of Part A.

$$
\begin{array}{lr}
\sigma_{\mathrm{A}}=\frac{2}{J} \mu_{\mathrm{A}}(\theta) \ln \left(\overline{\mathbf{V}}_{\mathrm{A}}^{\mathrm{e}}\right) & \text { elastic response } \\
\sigma_{\mathrm{D}}=\sigma_{\mathrm{A}} & \text { driving stress } \\
g\left(\sigma_{\mathrm{D}}\right)=\sqrt{\frac{3}{2} \sigma_{\mathrm{D}}^{\prime}: \sigma_{\mathrm{D}}^{\prime}}=\sigma_{\mathrm{D}}^{\mathrm{vm}} \geq 0 & \text { plastic potential } \\
\mathbf{D}_{\mathrm{A}}^{\mathrm{p}}=\dot{p} \frac{3 \sigma_{\mathrm{D}}^{\prime}}{2 \sigma_{\mathrm{D}}^{\mathrm{vm}}=\mathbf{F}_{\mathrm{A}}^{\mathrm{e}} \dot{\mathbf{F}}_{\mathrm{A}}^{\mathrm{p}} \mathbf{F}_{\mathrm{A}}^{-1}} & \text { plastic rate-of-deformation } \\
\sigma_{\mathrm{V}}=\sum_{x=\alpha, \beta} \frac{k_{B} \theta}{V_{x}} \operatorname{arsinh}\left(\frac{\dot{p}}{\dot{p}_{0, x}^{*}} \exp \left[\frac{\Delta H_{x}}{R \theta}\right]\right) & \text { viscous stress }
\end{array}
$$

A semi-implicit stress-update algorithm is used to integrate these equations in time, which implies that the direction of plastic flow $\mathbf{N}$ and the absolute temperature $\theta$ lag one time step behind. Using the relation for the plastic rate-of-deformation tensor in Box 1, the inverse plastic deformation gradient is estimated by the relation

$$
\left(\mathbf{F}_{\mathrm{A}, n+1}^{\mathrm{p}, i}\right)^{-1}=\left(\mathbf{1}-\Delta p_{n+1}^{i} \mathbf{F}_{n+1}^{-1} \mathbf{N}_{n} \mathbf{F}_{n+1}\right)\left(\mathbf{F}_{\mathrm{A}, n}^{\mathrm{p}}\right)^{-1}
$$

where $i$ denotes the current iteration in time step $n+1, \Delta p_{n+1}^{i}=\dot{p}_{n+1}^{i} \Delta t_{n+1}$ is the equivalent plastic strain increment, and $\mathbf{N}_{n}$ is the direction of plastic flow calculated from the previous time step, i.e.,

$$
\mathbf{N}_{n}=\frac{3}{2} \frac{\sigma_{\mathrm{D}, n}^{\prime}}{\sigma_{\mathrm{D}, n}^{\mathrm{vm}}}
$$

The elastic deformation gradient is then calculated as

$$
\mathbf{F}_{\mathrm{A}, n+1}^{\mathrm{e}, i}=\mathbf{F}_{n+1}\left(\mathbf{F}_{\mathrm{A}, n+1}^{\mathrm{p}, i}\right)^{-1}
$$

which gives us the driving stress, $\boldsymbol{\sigma}_{\mathrm{D}, n+1}^{i}$ and the von Mises equivalent stress $\sigma_{\mathrm{D}, n+1}^{\mathrm{vm}, i}$, see Box 1 . The constitutive relations for the two dashpots give a residual function in the form

$$
f\left(\dot{p}_{n+1}^{i}\right)=f_{n+1}^{i}=\sigma_{\mathrm{D}, n+1}^{\mathrm{vm}, i}-\sigma_{\mathrm{V}, n+1}^{i}=0
$$

where the viscous stress $\sigma_{\mathrm{V}, n+1}^{i}$ is defined in Box 1. Using the secant method, an updated value of the equivalent plastic strain rate is obtained by

$$
\dot{p}_{n+1}^{i+1}=\dot{p}_{n+1}^{i}-f_{n+1}^{i} \frac{\dot{p}_{n+1}^{i}-\dot{p}_{n+1}^{i-1}}{f_{n+1}^{i}-f_{n+1}^{i-1}}
$$


The iteration procedure continues until a convergence criterion is fulfilled. Note that the iterative scheme is not self-started. In iteration $i=1$ of the first increment the equivalent plastic strain rates $\dot{p}_{1}^{0}$ and $\dot{p}_{1}^{1}$ have to be estimated, while in the remaining increments $\dot{p}_{n}^{1}$ is set equal to the converged value from the previous increment $\dot{p}_{n}$ and $\dot{p}_{n}^{0}$ is kept constant and equal to $\dot{p}_{1}^{0}$.

Concerning Part B of the rheological model, the stress tensor $\sigma_{\mathrm{B}, n+1}$ is given explicitly by the deformation gradient $\mathbf{F}_{n+1}$ and the temperature from the previous timestep $\theta_{n}$, i.e.,

$$
\boldsymbol{\sigma}_{\mathrm{B}, n+1}=\frac{\mu_{\mathrm{B}}\left(\theta_{n}\right) \lambda_{\text {lock }}}{3 \bar{\lambda}_{\mathrm{c}, n+1}} \mathcal{L}^{-1}\left(\frac{\bar{\lambda}_{\mathrm{c}, n+1}}{\lambda_{\text {lock }}}\right) \overline{\mathbf{B}}_{n+1}^{\prime}+\kappa\left(\theta_{n}\right) \ln \left(J_{n+1}\right) \mathbf{1}-3 \kappa\left(\theta_{n}\right) \alpha\left(\theta_{n}-\theta_{0}\right) \mathbf{1}
$$

Following the work of Miehe [37] and Sun et al. [38], the consistent tangent operator, $\mathbf{C}^{\mathrm{t}}$, is found by numerical differentiation. The deformation gradient is perturbed in such a way that only one of the six unique components of the rate-of-deformation tensor is changed at the time, i.e.,

$$
\Delta \mathbf{F}_{ \pm}^{(k l)}= \pm \frac{\epsilon}{2}\left[\left(\mathbf{e}_{k} \otimes \mathbf{e}_{l}\right) \mathbf{F}+\left(\mathbf{e}_{l} \otimes \mathbf{e}_{k}\right) \mathbf{F}\right]
$$

where $\epsilon$ is the perturbation coefficient set equal to $10^{-8}$ and $\mathbf{e}_{k}$ for $k=1,2,3$ are the Cartesian base vectors. The perturbed deformation gradient, $\hat{\mathbf{F}}^{(k l)}$, is then obtained as

$$
\hat{\mathbf{F}}_{ \pm}^{(k l)}=\mathbf{F}+\Delta \mathbf{F}_{ \pm}^{(k l)}
$$

For each of the twelve deformation gradients thus obtained, the Cauchy stress tensor $\sigma\left(\hat{\mathbf{F}}^{(k l)}\right)$ is calculated. Using a central difference scheme, the consistent tangent operator $\mathbf{C}^{\mathbf{t}}$ is estimated as

$$
C_{i j(k l)}^{\mathrm{t}}=\frac{\sigma_{i j}\left(\hat{\mathbf{F}}_{+}^{(k l)}\right)-\sigma_{i j}\left(\hat{\mathbf{F}}_{-}^{(k l)}\right)}{2 \epsilon}
$$

In Voigt notation this means that for each plus-minus perturbation of the deformation gradient, we obtain column $(k l)$ in the $6 \times 6$ tangent operator $\left[\mathbf{C}^{\mathrm{t}}\right]$ with row indices $i j=11,22,33,12,13,23$.

To ensure convergence, sub-stepping is used to limit the strain increment during the time step. The number of sub-steps, $N$, is controlled by the criterion

$$
N=\max \left\{\operatorname{nint}\left[\frac{\Delta \varepsilon_{\mathrm{eq}}}{\varepsilon_{\mathrm{cr}}}+0.5\right], 1\right\}
$$

where nint is the nearest integer function, $\Delta \varepsilon_{\mathrm{eq}}=\sqrt{\frac{2}{3} \Delta \boldsymbol{\varepsilon}^{\prime}: \Delta \boldsymbol{\varepsilon}^{\prime}}$ is the equivalent logarithmic strain increment, $\Delta \boldsymbol{\varepsilon}^{\prime}=\Delta \boldsymbol{\varepsilon}-\frac{1}{3} \operatorname{tr}(\Delta \boldsymbol{\varepsilon}) \mathbf{1}$ is the deviatoric logarithmic strain tensor obtained by integrating the rate-ofdeformation tensor $\mathbf{D}$ over the time increment [47]

$$
\Delta \boldsymbol{\varepsilon}=\int_{t_{n}}^{t_{n+1}} \mathbf{D} \mathrm{d} t
$$


where $n$ and $n+1$ denote the previous and current time step, respectively. Furthermore, $\varepsilon_{\mathrm{cr}}$ is a critical value set equal to strain-to-yield. If $N>1$, new deformation gradients are calculated from the velocity gradient at the beginning of the time step, i.e.,

$$
\mathbf{L}_{n}=\frac{\mathbf{F}_{n+1}-\mathbf{F}_{n}}{\Delta t_{n+1}}\left(\mathbf{F}_{n}\right)^{-1}
$$

For sub-step number $q$, the deformation gradient, $\mathbf{F}_{q}$ is then calculated as

$$
\mathbf{F}_{q}=\left(\mathbf{1}+\frac{q \Delta t_{n+1}}{N} \mathbf{L}_{n}\right) \mathbf{F}_{n} \quad \text { for } \quad q \in[1, N]
$$

\section{Material model calibration}

Direct calibration from the experimental data was performed to obtain initial values of the parameters in the constitutive model. These initial values were then used in an optimization procedure. A brief review of the direct calibration procedure is given in the following.

\subsection{Shear modulus}

Young's modulus $E$ was found by linear regression of the Cauchy stress vs. longitudinal logarithmic strain curve for strain magnitudes of $\varepsilon_{\mathrm{L}} \in[0,0.025]$. The shear modulus $\mu$ could then be computed from the relation

$$
\mu=\frac{E}{2(1+v)}
$$

where $v=\left|\frac{\mathrm{d} \varepsilon_{\mathrm{T}}}{\mathrm{d} \varepsilon_{\mathrm{L}}}\right| \approx 0.49$ is Poisson's ratio found by numerical differentiation of the transverse strain $\left(\varepsilon_{\mathrm{T}}\right)$ vs. longitudinal strain $\left(\varepsilon_{\mathrm{L}}\right)$ curves given in Johnsen et al. [11].

As shown in Figure 5, a clear strain rate and temperature dependence of the shear modulus was observed. This strain rate dependence of the shear modulus has been neglected in Equation (15). The material parameters in Equation (15) were found to be equal to $\mu_{\mathrm{A} \text {,ref }}=46 \mathrm{MPa}$ and $a_{\mathrm{A}}=0.03 \mathrm{~K}^{-1}$ from a least squares fit to the experimentally obtained shear moduli, see Figure 5 .

\subsection{Flow stress}

The coefficients in the Ree-Eyring flow model [6] were identified from the stress-strain curves by using the flow stress, $\sigma_{0.15}$, at a fixed strain magnitude of $\varepsilon_{\mathrm{L}}=0.15$ for all investigated temperatures and strain rates. The least squares fit of Equation (20) to the experimental data is shown in Figure 6 along with the obtained parameters in Table 2 . 


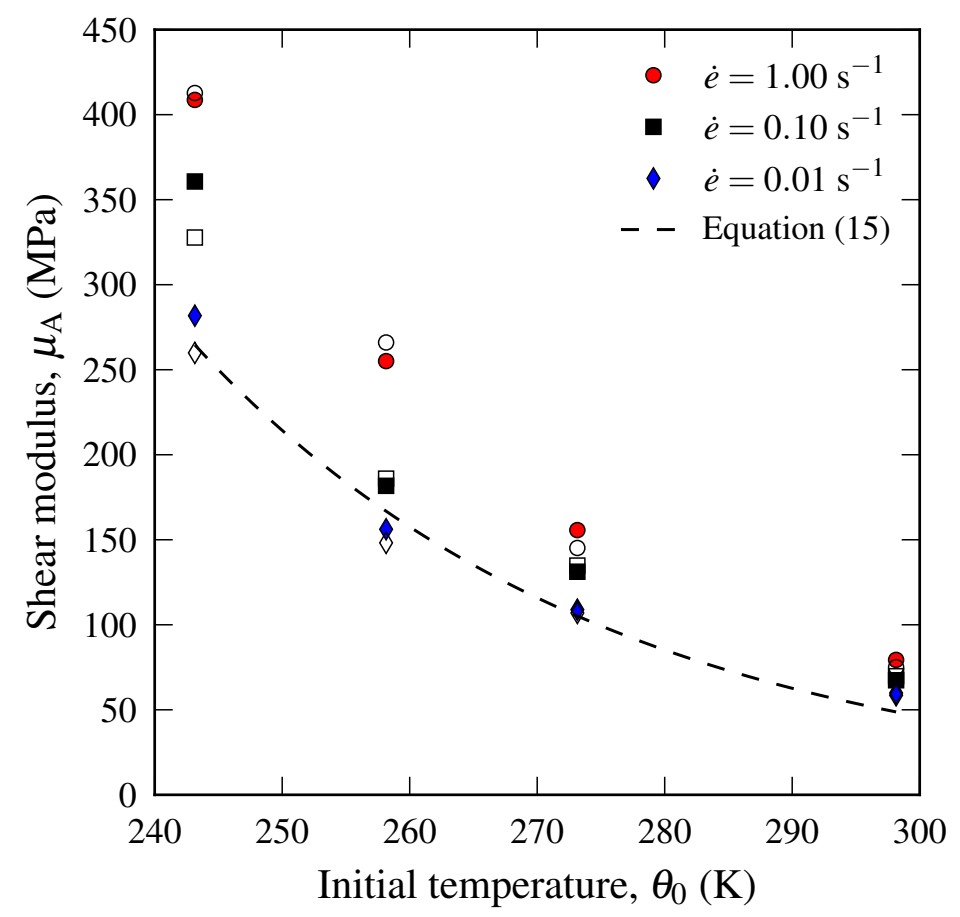

Figure 5: Temperature and strain rate dependence of the shear modulus of the material. Data adapted from [11].

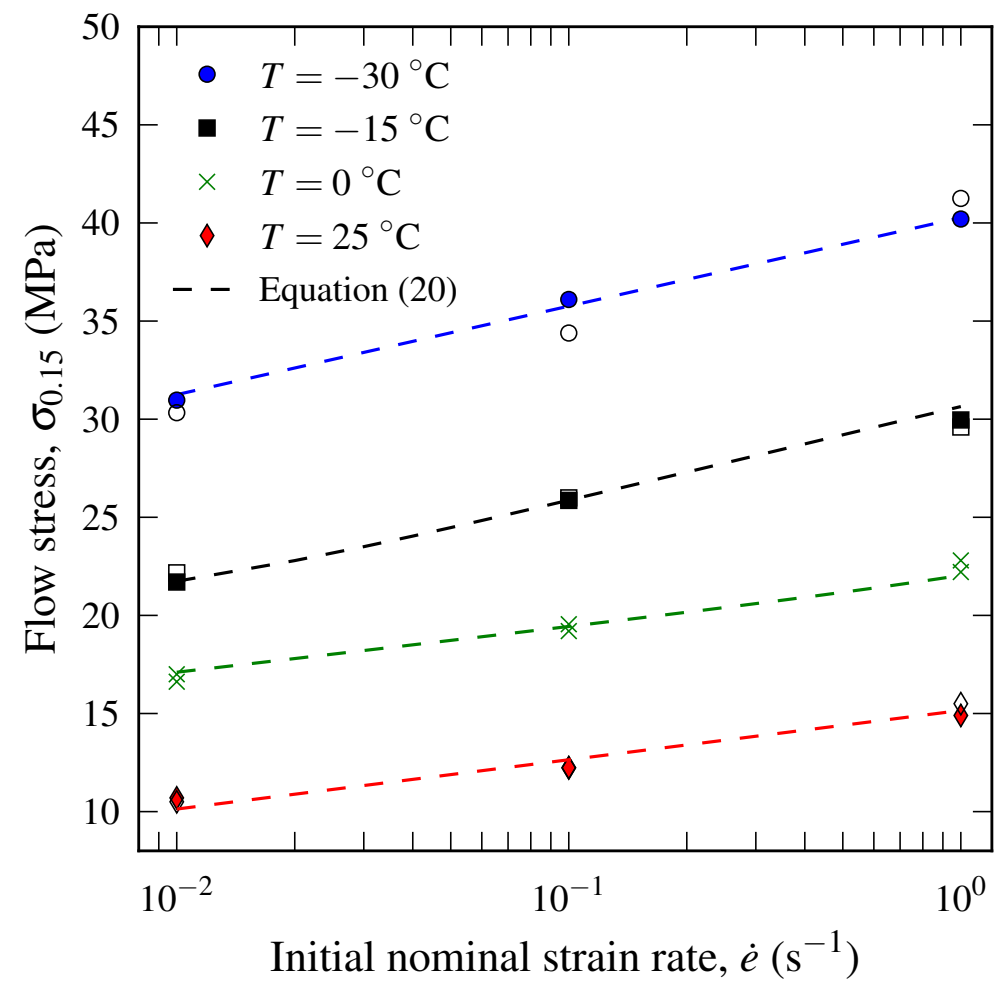

Figure 6: Temperature and strain rate dependence on the flow stress of the material. Data taken from [11]. 
Table 2: Initial material parameters (before optimization) in the Ree-Eyring model, Equation 20].

\begin{tabular}{cccccccc}
\hline $\begin{array}{c}k_{B} \\
(\mathrm{~J} / \mathrm{K})\end{array}$ & $\begin{array}{c}R \\
(\mathrm{~J} /(\mathrm{mol} \cdot \mathrm{K}))\end{array}$ & $\begin{array}{c}V_{\alpha} \\
\left(\mathrm{nm}^{3}\right)\end{array}$ & $\begin{array}{c}\dot{p}_{0, \alpha} \\
\left(\mathrm{s}^{-1}\right)\end{array}$ & $\begin{array}{c}\Delta H_{\alpha} \\
(\mathrm{kJ} / \mathrm{mol})\end{array}$ & $\begin{array}{c}V_{\beta} \\
\left(\mathrm{nm}^{3}\right)\end{array}$ & $\begin{array}{c}\dot{p}_{0, \beta} \\
\left(\mathrm{s}^{-1}\right)\end{array}$ & $\begin{array}{c}\Delta H_{\beta} \\
(\mathrm{kJ} / \mathrm{mol})\end{array}$ \\
\hline $1.38 \cdot 10^{-23}$ & 8.314 & 3.45 & $1.38 \cdot 10^{28}$ & 188.6 & 3.10 & $5.79 \cdot 10^{39}$ & 204.3 \\
\hline
\end{tabular}

\subsection{Strain hardening}

There are two contributions to strain hardening in the model: (1) orientational hardening $\sigma_{\mathrm{B}}$ in Part B capturing the effect of polymer chain alignment, and (2) isotropic hardening from the deformation dependent reference strain rates in the viscous dashpots in Part A.

The orientational hardening is modelled by the eight chain spring [5]. Simply put, the spring accounts for how the polymer chains align due to stretching and give rise to the abrupt change in strain hardening when approaching the locking stretch. To estimate the value of the reference shear modulus $\mu_{\mathrm{B}, \text { ref }}$ and the locking stretch, $\lambda_{\text {lock}}$, a simple one-dimensional (1D) model was used. First we calculate the axial component of the stress from Equation (37) as

$$
\sigma=\frac{\mu_{\mathrm{B}}(\theta) \lambda_{\text {lock }}}{3 J \bar{\lambda}_{\mathrm{c}}} \mathcal{L}^{-1}\left(\frac{\bar{\lambda}_{\mathrm{c}}}{\lambda_{\text {lock }}}\right)\left(\bar{\lambda}^{2}-\bar{\lambda}_{\mathrm{c}}^{2}\right)
$$

where $J=\lambda^{1-2 v}$ and $\bar{\lambda}_{\mathrm{c}}=\sqrt{\frac{1}{3}\left(\bar{\lambda}^{2}+\frac{2}{\bar{\lambda}^{2 v}}\right)}$. Using a Poisson's ratio $v$ equal to 0.49 and comparing the onset of strain hardening from Equation (62) with that from the experimental stress-strain curve at the reference temperature $\theta_{\text {ref }}=298.15 \mathrm{~K}$, we find the values $\mu_{\mathrm{B}, \text { ref }}=2.0 \mathrm{MPa}$ and $\lambda_{\text {lock }} \approx 5.2$.

Next, the deformation dependent reference strain rates are found by fitting the expression for the viscous stress, $\sigma_{\mathrm{V}}$ in Equation (19), to the flow stress minus the stress contribution from Part B at different levels of deformation while keeping all parameters except the reference strain rate constant. From Figure 7 it is readily seen that there is a decrease in the reference strain rates as the deformation is increased. Equation (21) is proposed to describe the deformation dependence of the reference strain rates $\dot{p}_{0, \alpha}^{*}$ and $\dot{p}_{0, \beta}^{*}$. A least squares fit of Equation (21) to the data in Figure 7 yielded the initial values: $b_{\alpha}=7.2$ and $b_{\beta}=12.0$.

\subsection{Material parameters}

The material parameters obtained in the previous sections were used as initial values in a numerical optimization procedure where simulations were run and the parameters varied manually to fit the experimental 


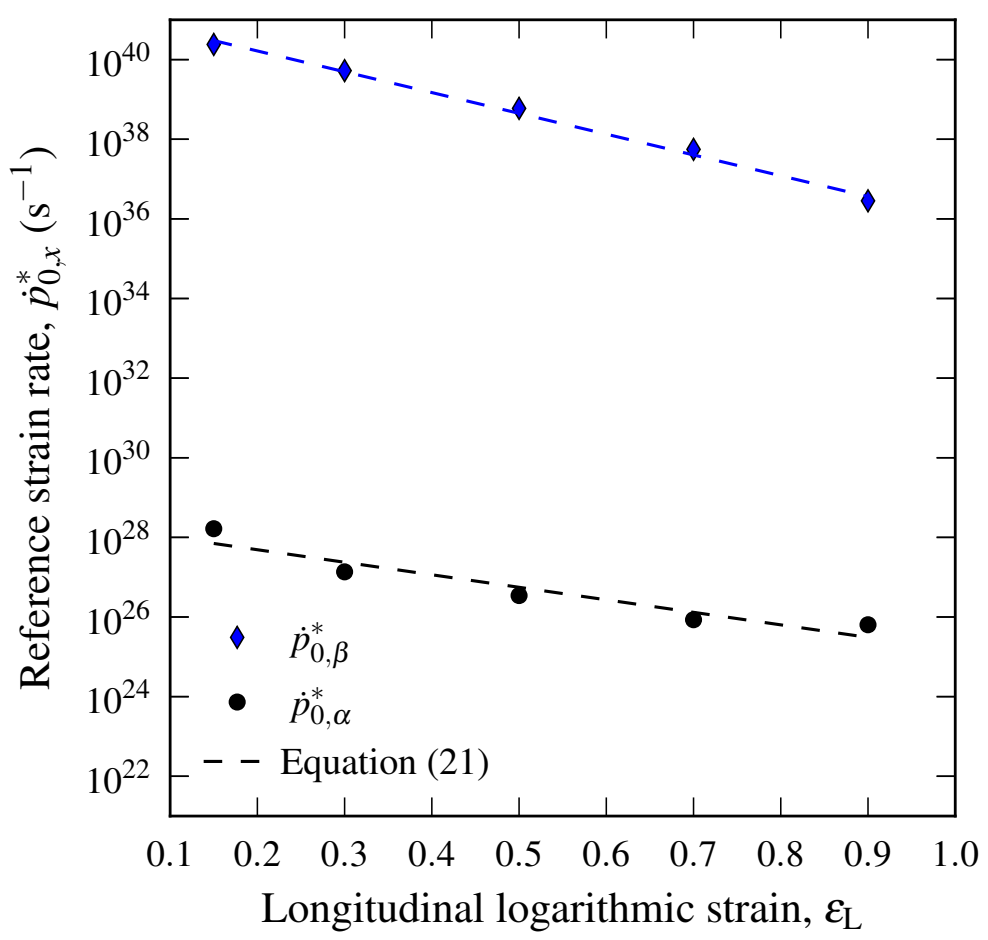

Figure 7: Reference strain rates, $\dot{p}_{0, x}^{*}$, as a function of longitudinal logarithmic strain. subsequent numerical simulations are presented in Table 3

Table 3: Optimized parameters in constitutive model.

\begin{tabular}{|c|c|c|c|c|c|c|c|c|c|c|c|}
\hline Part A & $\begin{array}{l}\mu_{\mathrm{A}, \mathrm{ref}} \\
(\mathrm{MPa})\end{array}$ & $\begin{array}{c}a_{\mathrm{A}} \\
\left(\mathrm{K}^{-1}\right)\end{array}$ & $\begin{array}{l}\theta_{\text {ref }} \\
(\mathrm{K})\end{array}$ & $\begin{array}{c}\Delta H_{\alpha} \\
(\mathrm{kJ} / \mathrm{mol})\end{array}$ & $\begin{array}{c}V_{\alpha} \\
\left(\mathrm{nm}^{3}\right)\end{array}$ & $\begin{array}{l}\dot{p}_{0, \alpha} \\
\left(\mathrm{s}^{-1}\right)\end{array}$ & $\begin{array}{l}b_{\alpha} \\
(-)\end{array}$ & $\begin{array}{c}\Delta H_{\beta} \\
(\mathrm{kJ} / \mathrm{mol})\end{array}$ & $\begin{array}{c}V_{\beta} \\
\left(\mathrm{nm}^{3}\right)\end{array}$ & $\begin{array}{l}\dot{p}_{0, \beta} \\
\left(\mathrm{s}^{-1}\right)\end{array}$ & $\begin{array}{l}b_{\beta} \\
(-)\end{array}$ \\
\hline & 46 & 0.028 & 298.15 & 179.5 & 4.72 & $2.36 \cdot 10^{25}$ & 3.0 & 196.1 & 3.19 & $6.13 \cdot 10^{36}$ & 10.0 \\
\hline Part B & $\begin{array}{l}\mu_{\mathrm{B}, \mathrm{ref}} \\
(\mathrm{MPa})\end{array}$ & $\begin{array}{c}\lambda_{\text {lock }} \\
(-)\end{array}$ & $\begin{array}{l}v \\
(-)\end{array}$ & & & & & & & & \\
\hline & 2.0 & 5.2 & 0.49 & & & & & & & & \\
\hline
\end{tabular}

data. An alternative would have been to use an optimization software. The material parameters used in the

\section{Finite element model}

All simulations were run in the commercial finite element program Abaqus/Standard, with the constitutive model implemented through a UMAT subroutine. Due to the symmetry of the tensile specimen and to 

degree of freedom (CAX4RT) were used in all simulations with an element size of approximately $0.1 \mathrm{~mm}$ $\times 0.05 \mathrm{~mm}$ in the parallel part. Only a $1 \mathrm{~mm}$ portion of the grips was included in the model to further

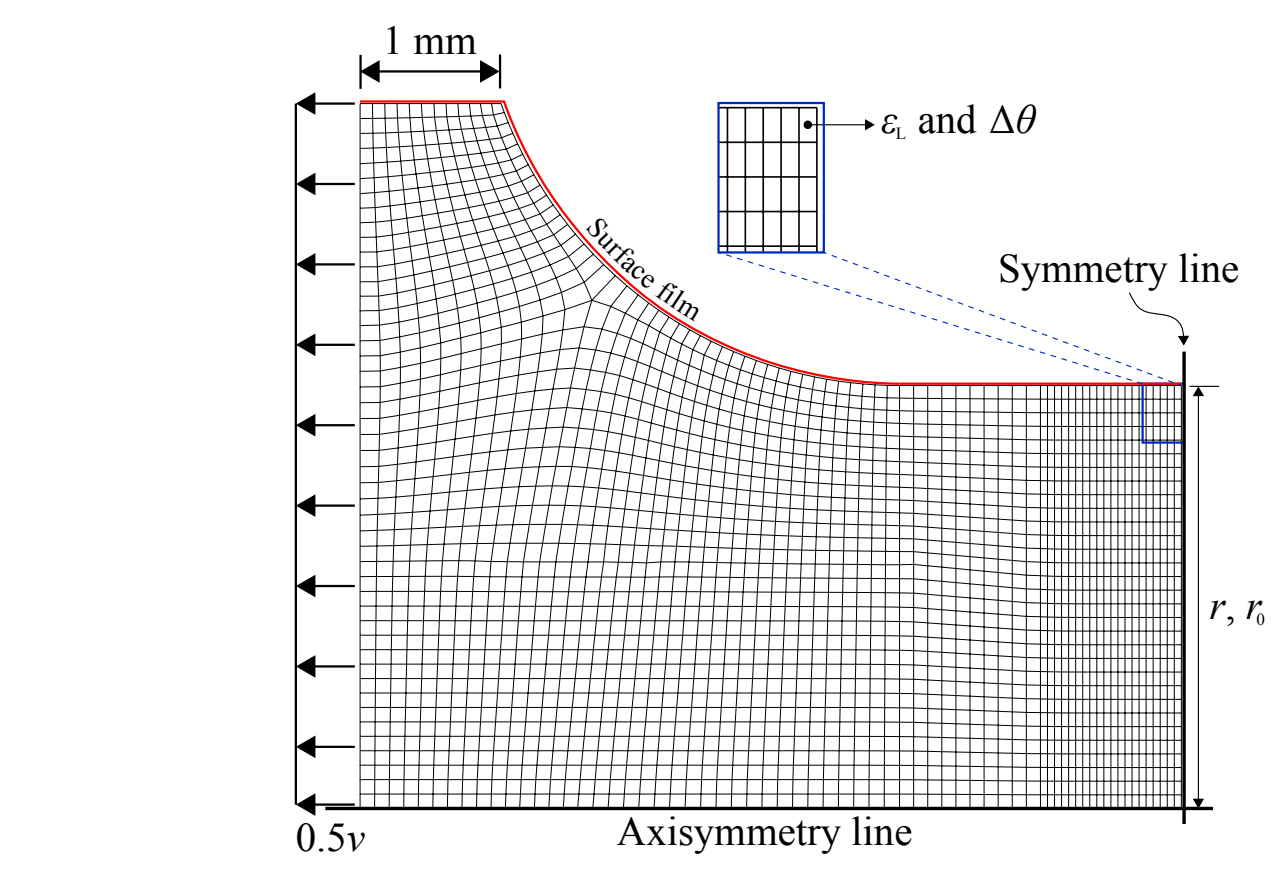

Figure 8: Axisymmetric finite element model with mesh and boundary conditions.

save computational time, axisymmetric boundary conditions were employed in addition to one symmetry plane, as indicated in Figure 8 . Consequently, the transverse deformation anisotropy observed in the experimental tests is not included. Four-node axisymmetric elements with reduced integration and one thermal

reduce the computational time. The cross-head velocity, $v$, of the testing machine was applied as a velocity boundary condition at the positions indicated in Figure 8 . Self-heating, $\Delta \theta$, and longitudinal strain, $\varepsilon_{\mathrm{L}}$, were extracted from the indicated element in Figure 8, while the transverse strains were calculated as an average over the cross section at the symmetry line, i.e., $\varepsilon_{1}=\varepsilon_{2}=\ln \left(r / r_{0}\right)$, where $r$ and $r_{0}$ are the current and initial radius of the parallel section, respectively. The Cauchy stress was then found using Equation (1), where $\lambda_{1}=\lambda_{2}=\exp \left(\varepsilon_{1}\right)$ is used to calculate the current area $A$ and the force $F$ is extracted from the boundary conditions on the symmetry line.

In addition to the mechanical boundary conditions, a surface film was applied on the free surface of the tensile specimen, see the area highlighted with red in Figure 8. The surface film was used to simulate heat convection to air. Heat conduction within the material itself and heat convection to the surroundings were handled by the thermal solver in Abaqus. The values of the heat convection to air parameter, $h_{c}$, the thermal 
conductivity, $k$, and the specific heat capacity, $C_{\mathrm{p}}$, are given in Table 1 . Lastly, the entire axisymmetric model was given an initial temperature equal to the surrounding temperature using the predefined field feature in Abaqus/Standard.

\section{Results and discussion}

A comparison of the numerical results and the experimental results obtained by Johnsen et al. [11] are presented in the following. All numerical and experimental values were obtained from uniaxial tension tests. Note that the results from the repeat tests presented in [11] are omitted, thus only the representative experimental results are included in this study.

\subsection{Stress-strain curves}

Figure 9 presents the axial component of the Cauchy stress tensor as a function of the longitudinal logarithmic strain from both simulations and experiments. Twelve configurations of temperature and strain rate were investigated in total: four temperatures $T$ of $25{ }^{\circ} \mathrm{C}, 0{ }^{\circ} \mathrm{C},-15{ }^{\circ} \mathrm{C}$ and $-30{ }^{\circ} \mathrm{C}$ and for each temperature three nominal strain rates $\dot{e}$ of $0.01 \mathrm{~s}^{-1}, 0.1 \mathrm{~s}^{-1}$ and $1.0 \mathrm{~s}^{-1}$.

As shown in Figure 9, the overall behaviour of the material is well described by the constitutive model, although the strain rate effect on Young's modulus (Figure 5) is not captured since viscoelasticity is not incorporated. It appears from Figure 9 that the yield stress is accurately represented for all test configurations by the incorporated Ree-Eyring [6] flow theory. Furthermore, we see that the strain hardening is well described up to the onset of network hardening for all configurations except at room temperature. At room temperature the onset of network hardening occurs too early in the simulations. However, as seen from Figure 9, the onset of network hardening is continuously shifted to higher strain levels as the temperature is decreased. This is caused by the constant locking stretch in combination with the reduced shear modulus (Equation (31)) for decreasing temperatures in Part B of the constitutive model.

\subsection{Volume change}

The volumetric strain from the simulations was calculated using the longitudinal strain from the indicated element in Figure 8 and the average transverse strain over the cross section, viz.

$$
\varepsilon_{\mathrm{V}}=\varepsilon_{\mathrm{L}}+2 \varepsilon_{1}=\varepsilon_{\mathrm{L}}+2 \ln \left(\frac{r}{r_{0}}\right)
$$




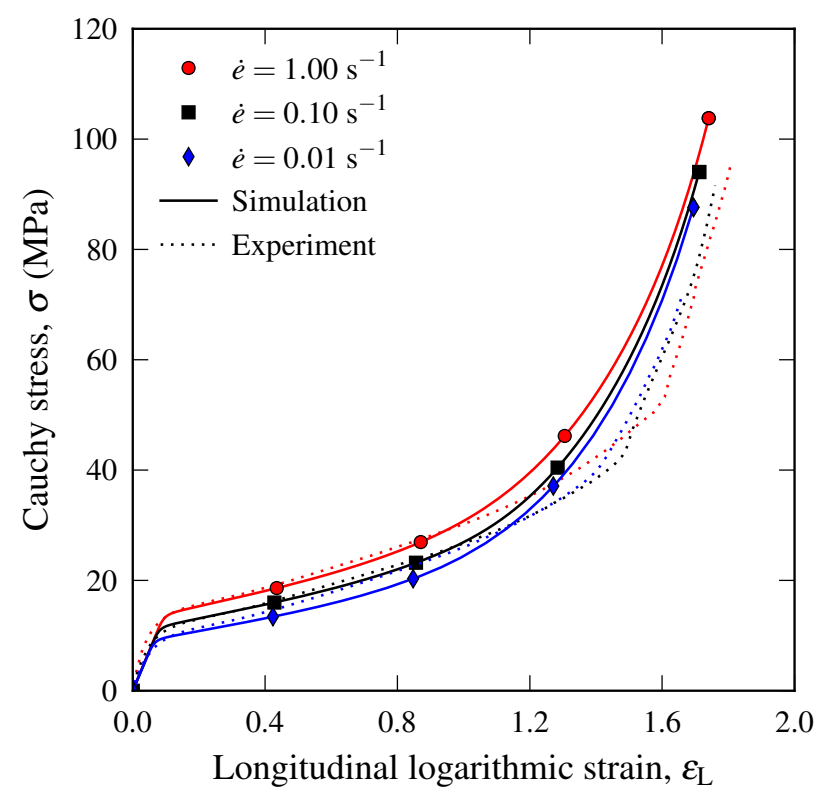

(a) $T=25^{\circ} \mathrm{C}$

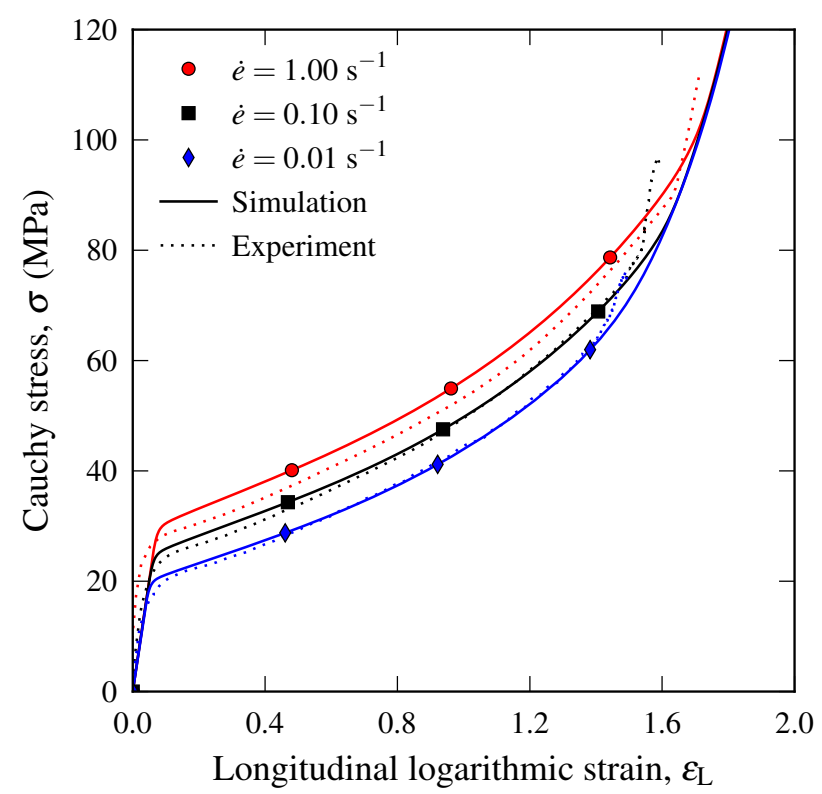

(c) $T=-15^{\circ} \mathrm{C}$

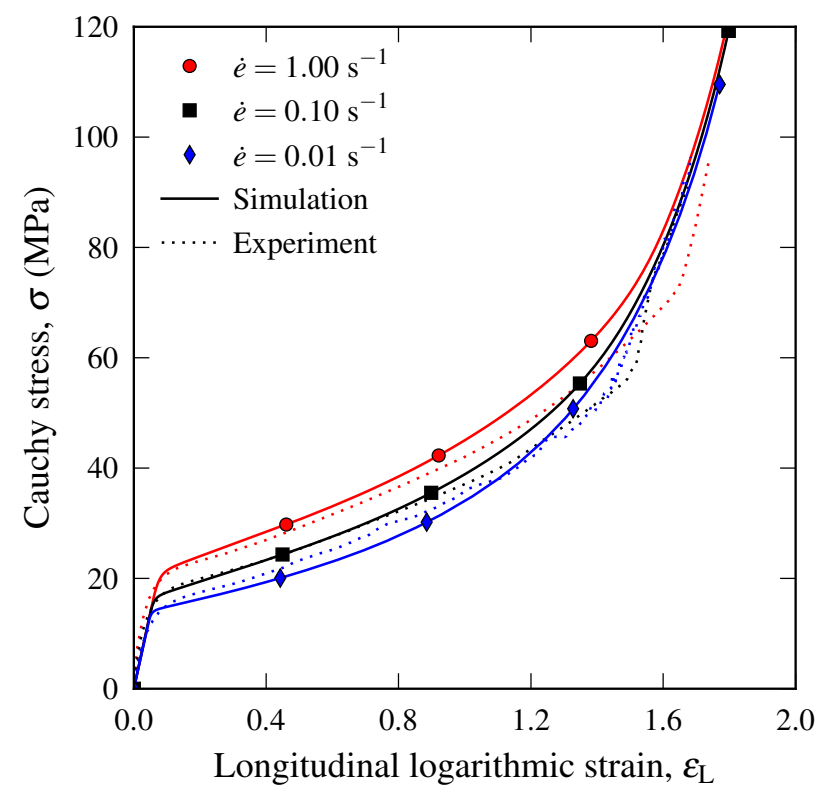

(b) $T=0{ }^{\circ} \mathrm{C}$

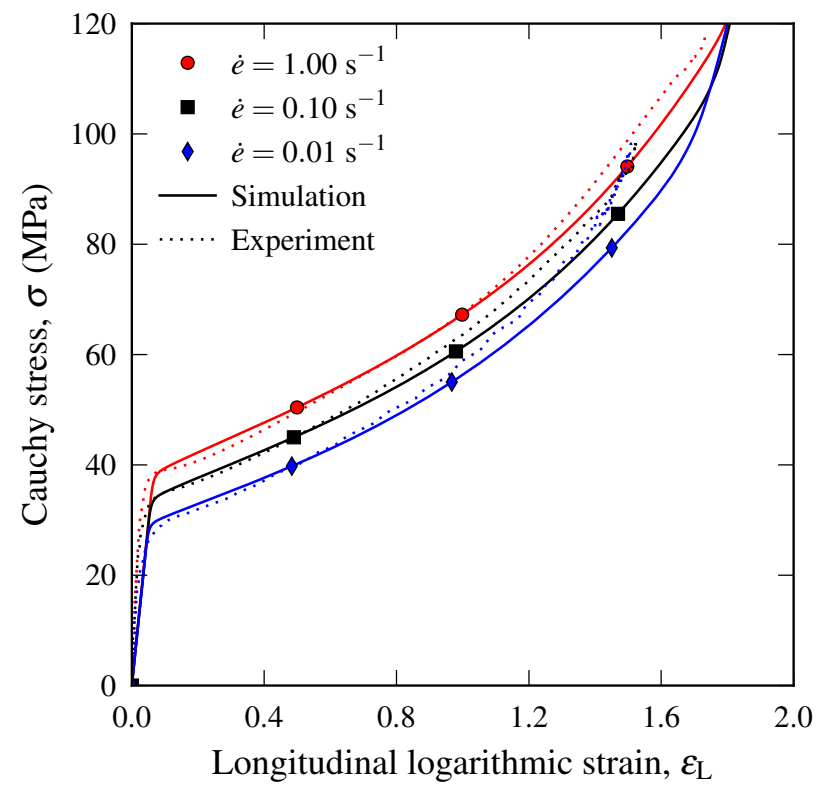

(d) $T=-30{ }^{\circ} \mathrm{C}$

Figure 9: Cauchy stress vs. longitudinal logarithmic strain from uniaxial tension tests and numerical simulations at three different nominal strain rates, $\dot{e}=0.01 \mathrm{~s}^{-1}, \dot{e}=0.1 \mathrm{~s}^{-1}$, and $\dot{e}=1.0 \mathrm{~s}^{-1}$, and at four different temperatures, (a) $T=25^{\circ} \mathrm{C},(\mathrm{b}) T=0{ }^{\circ} \mathrm{C}$, (c) $T=-15{ }^{\circ} \mathrm{C}$ and (d) $T=-30{ }^{\circ} \mathrm{C}$.

Figure 10 compares the volumetric strain from simulations and experiments for all test configurations.

Qualitative agreement between numerical predictions and experimental results is achieved at all investigated 


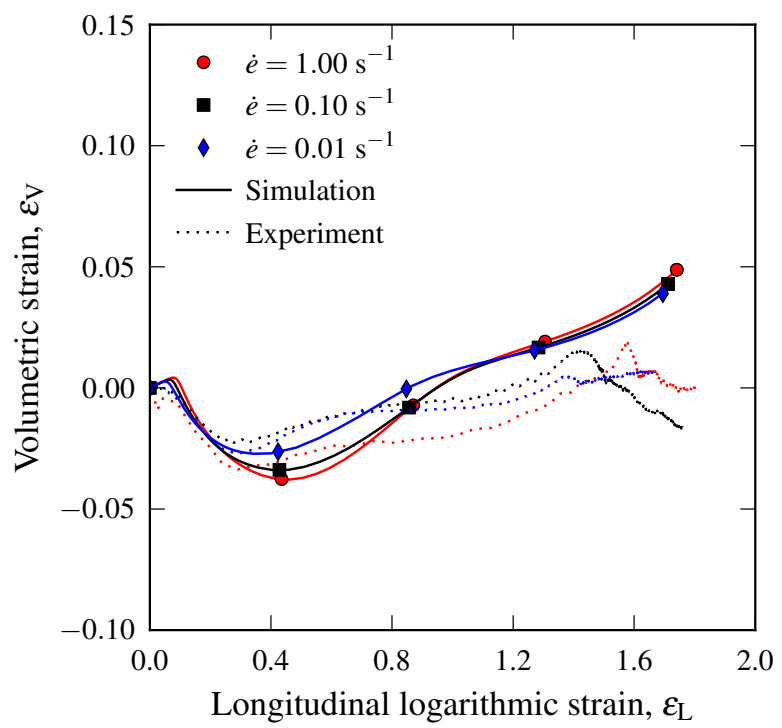

(a) $T=25^{\circ} \mathrm{C}$

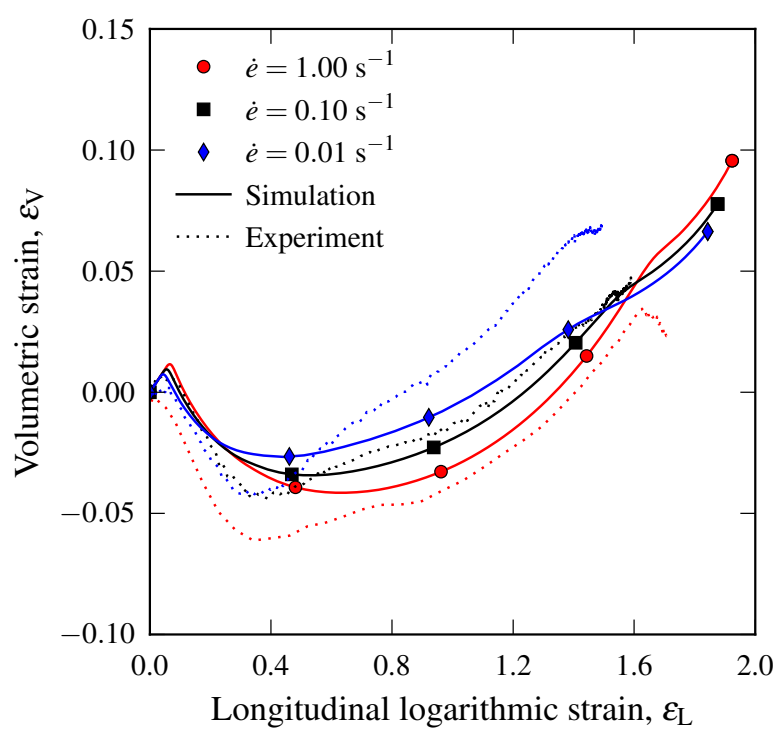

(c) $T=-15^{\circ} \mathrm{C}$

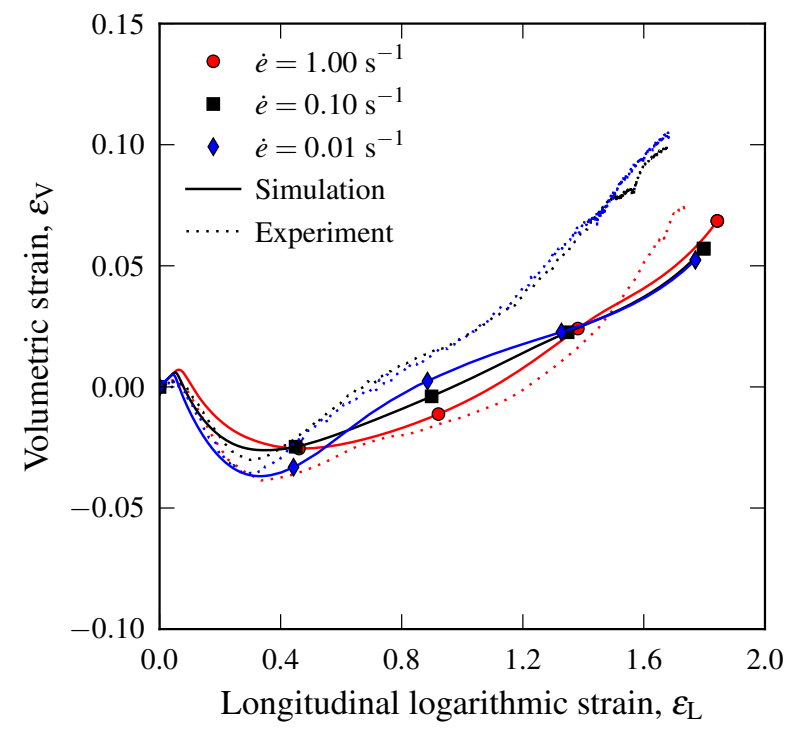

(b) $T=0{ }^{\circ} \mathrm{C}$

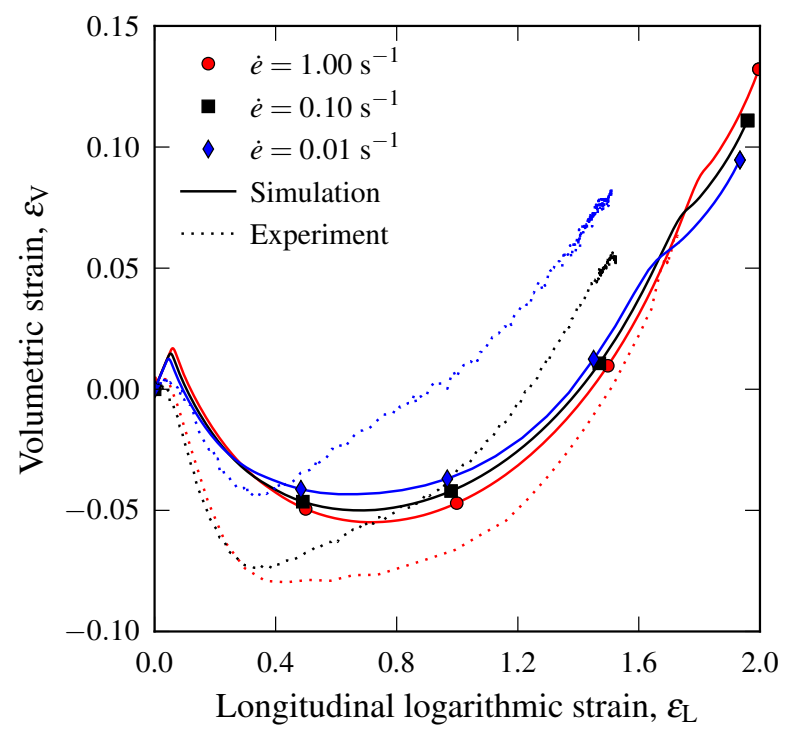

(d) $T=-30{ }^{\circ} \mathrm{C}$

Figure 10: Volumetric strain vs. longitudinal logarithmic strain from uniaxial tension tests and numerical simulations at three different nominal strain rates, $\dot{e}=0.01 \mathrm{~s}^{-1}, \dot{e}=0.1 \mathrm{~s}^{-1}$, and $\dot{e}=1.0 \mathrm{~s}^{-1}$, and at four different temperatures, (a) $T=25^{\circ} \mathrm{C}$, (b) $T=0$ ${ }^{\circ} \mathrm{C}$, (c) $T=-15{ }^{\circ} \mathrm{C}$ and (d) $T=-30{ }^{\circ} \mathrm{C}$.

temperatures. Due to the assumption of a constant Poisson's ratio, $v$, and the entropic nature of the bulk modulus in Part B, the model also captures the observed transition from an approximately incompressible material behaviour at room temperature to a more compressible behaviour at the lower temperatures. 
In agreement with what is observed in experiments [11], reducing the initial temperature results in more negative volumetric strain at moderate deformations in the numerical simulations. This is due to the formation of a more prominent neck, causing the strain field to become more heterogeneous. The heterogeneity of the strain field causes our method of calculating the volumetric strain, i.e., using the average longitudinal and transverse strain over the cross-section, to be less representative of the actual state inside the material, leading to the fictitious negative evolution of the volumetric strain in the beginning. A method to avoid this problem is to try estimating the heterogeneity of the strain field in the experiments, as proposed by Andersen [48] and used by Johnsen et al. [31]. However, since the volumetric strain presented in Figure 10 is calculated in a similar manner in experiments and simulations, this method was not further explored in this study.

\subsection{Self-heating}

The temperature increment due to self-heating in the material is given as a function of longitudinal logarithmic strain in Figure 11. Good qualitative agreement is found between simulations and experiments. In the uniaxial tension tests at the lowest strain rate, close to isothermal conditions are predicted. At the intermediate strain rate the predicted temperature increment from simulations is in good agreement with experimental observations. However, at the highest strain rate, the model does not generate enough heat. This is due to the interplay between the elastic and plastic components of Part A, see Figure 4b. Since the elastic stiffness in Part A is reduced for increasing temperature the consequence is a negative contribution to heat generation, which has to be compensated by the plastic dissipation in the viscous dashpots and the entropic spring in Part B. Furthermore, as the initial temperature decreases, the elastic stiffness increases, thus reducing elastic deformation and in effect the elastic rate-of-deformation. This is the reason why the constitutive model predicts a higher temperature increase as the initial temperature is lowered.

Another possible explanation for the observed discrepancies could be inaccuracies in the measured heat on the surface of the specimen during testing, along with uncertainties in the experimentally obtained thermal constants. The laser flash method [49] was used to obtain the specific heat capacity and the thermal conductivity. Due to limitations in the testing apparatus, it was not possible to measure the parameters at low temperatures. Consequently, the specific heat and thermal conductivity were estimated at three elevated temperatures of $25{ }^{\circ} \mathrm{C}, 35^{\circ} \mathrm{C}$ and $50{ }^{\circ} \mathrm{C}$. The thermal conductivity $(k=0.56 \mathrm{~W} /(\mathrm{m} \cdot \mathrm{K}))$ was more or less constant over the investigated temperatures with a standard deviation of $0.048 \mathrm{~W} /(\mathrm{m} \cdot \mathrm{K})$, while the specific heat varied almost linearly with temperature, see Johnsen et al. [31]. However, the values obtained at room 


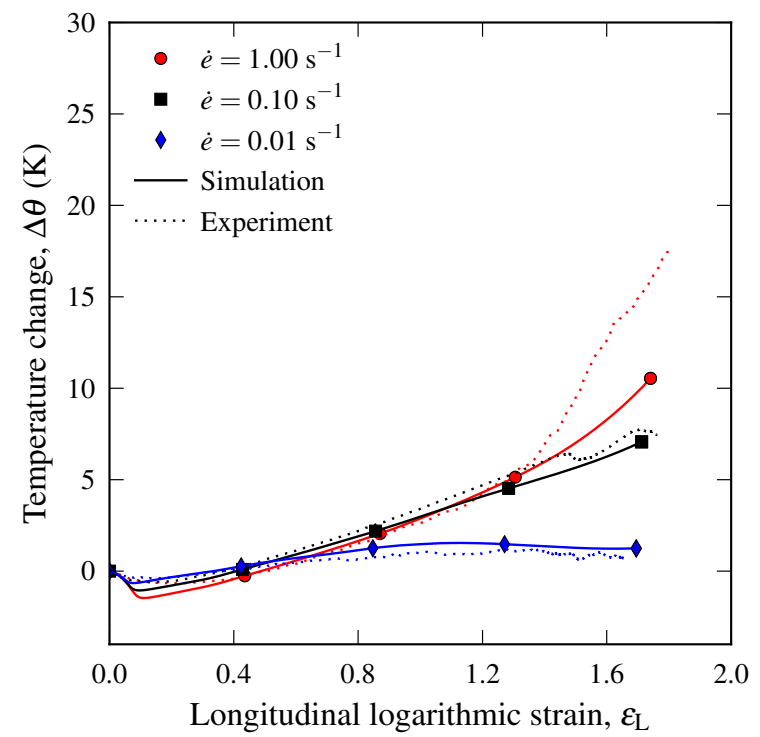

(a) $T=25^{\circ} \mathrm{C}$

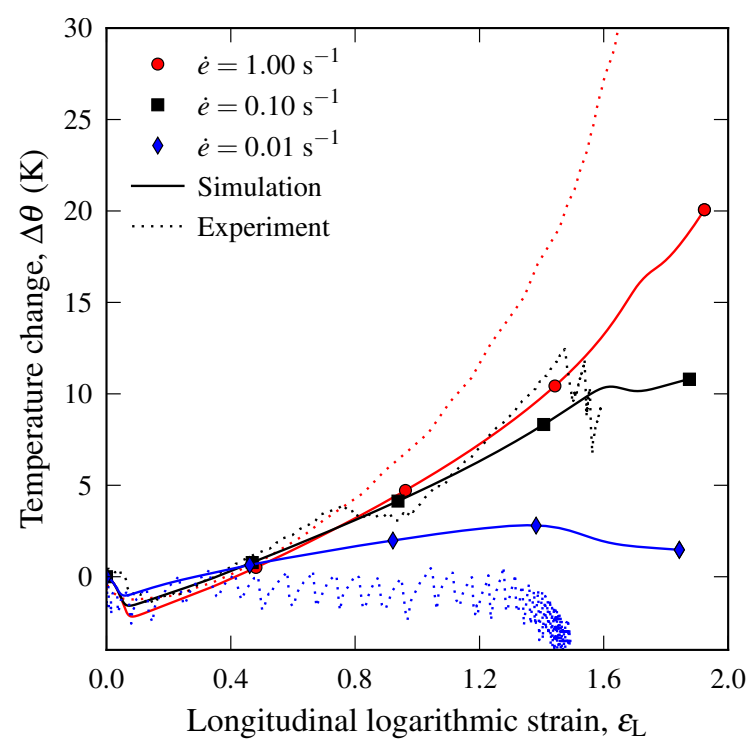

(c) $T=-15^{\circ} \mathrm{C}$

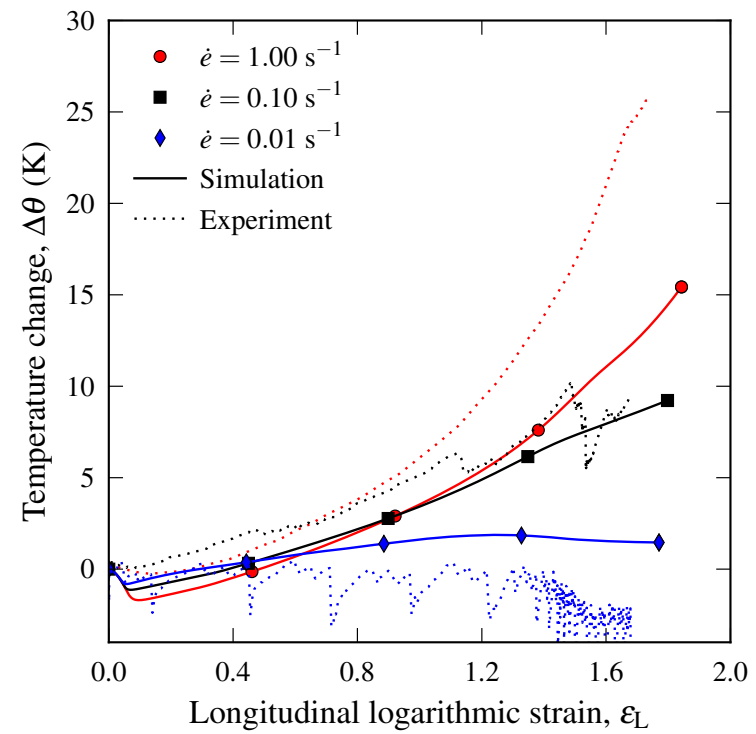

(b) $T=0{ }^{\circ} \mathrm{C}$

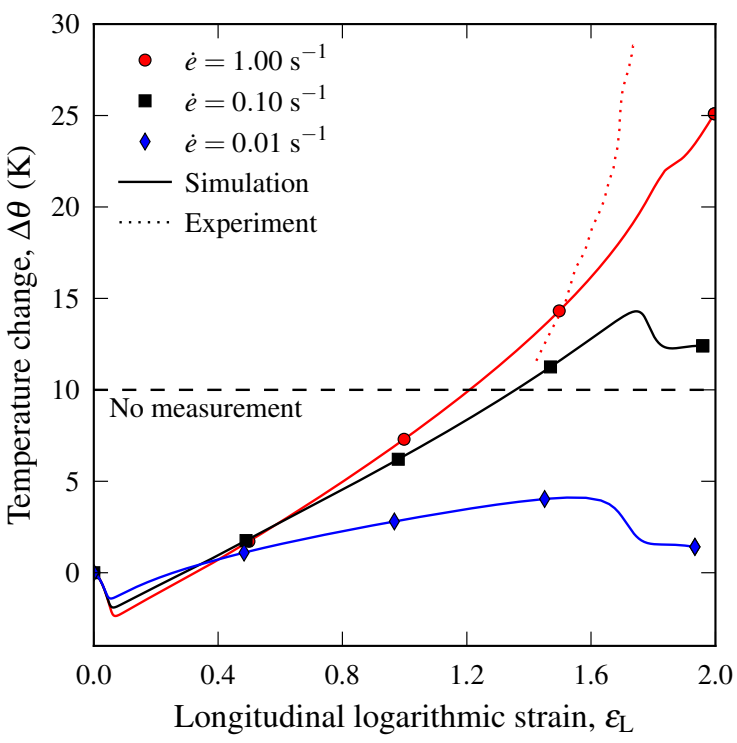

(d) $T=-30{ }^{\circ} \mathrm{C}$

Figure 11: Temperature change vs. longitudinal logarithmic strain from uniaxial tension tests and numerical simulations at three different nominal strain rates, $\dot{e}=0.01 \mathrm{~s}^{-1}, \dot{e}=0.1 \mathrm{~s}^{-1}$, and $\dot{e}=1.0 \mathrm{~s}^{-1}$, and at four different temperatures, (a) $T=25^{\circ} \mathrm{C}$, (b) $T=0$ ${ }^{\circ} \mathrm{C}$, (c) $T=-15{ }^{\circ} \mathrm{C}$ and (d) $T=-30{ }^{\circ} \mathrm{C}$.

temperature were used for both the specific heat capacity and the thermal conductivity in the simulations.

Note that the thermal camera used in the experiments by Johnsen et al. [11] was limited to temperatures above $-20{ }^{\circ} \mathrm{C}$, as indicated by the dashed line in Figure 11d. It should also be mentioned that the jagged 
shape of the temperature increment vs. longitudinal strain curves at temperatures below $25{ }^{\circ} \mathrm{C}$ is caused by the influx of liquid nitrogen during the tension test.

\subsection{Force-displacement curves}

As a further validation incorporating the response of the entire tension test sample, force vs. displacement curves are shown in Figure 12. The evolution of the force up to the peak value is well captured, along with the subsequent force drop. In the simulations of the room temperature experiments, the force levels are in general overestimated. This is attributed to a too high value of the shear modulus in Part B, in combination with a too low value of the locking stretch, thus overestimating the strain hardening. For the temperature $0{ }^{\circ} \mathrm{C}$, good agreement is found between simulation and experiment for the two lowest strain rates. At the highest strain rate there is not enough reduction in force after the peak force is reached, which for this configuration is caused by the deformation dependent reference strain rates. For the two lowest temperatures, a combination of the aforementioned effects is observed. At $-30{ }^{\circ} \mathrm{C}$ the force reduction is overestimated due to the reduced shear modulus in Part $\mathrm{B}\left(\mu_{\mathrm{B}} \approx \mu_{\mathrm{A}, \text { ref }} \cdot \frac{243.15}{298.15}=0.81 \mu_{\mathrm{A}, \text { ref }}\right)$, while at $-15^{\circ} \mathrm{C}$ the model underestimates the force reduction because of the isotropic hardening of the viscous dashpots.

\subsection{Strain rate}

As shown in Figure 13, there is an overall good agreement between the strain rate from simulations, extracted from the indicated element in Figure 8 , and the strain rate from experiments. At room temperature the strain rate in the simulations decreases too rapidly. This is due to strain hardening from Part B of the model, which decreases the strain rate by propagating the neck too early. As seen from Figure 13 this effect is continuously decreased as the initial temperature is reduced, which is caused by the reduced shear modulus in Part B. The reduced shear modulus delays the onset of network hardening, which again allows for a more prominent neck to form causing, or maintaining, the strain rate for a longer period before the neck starts to propagate and the strain rate goes down. Furthermore, when the neck is fully propagated, the strain rate stops decreasing and a sudden increase in strain rate is observed in all experiments and in the simulations at the two lowest temperatures. This is caused by the re-straining of the specimen which occurs when the neck is fully propagated to the shoulders.

\subsection{Strain-displacement curves}

A comparison of the local strain in the most deformed section of the specimen vs. the global displacement curves from simulations and experiments is given in Figure 14. The displacement in the finite element 


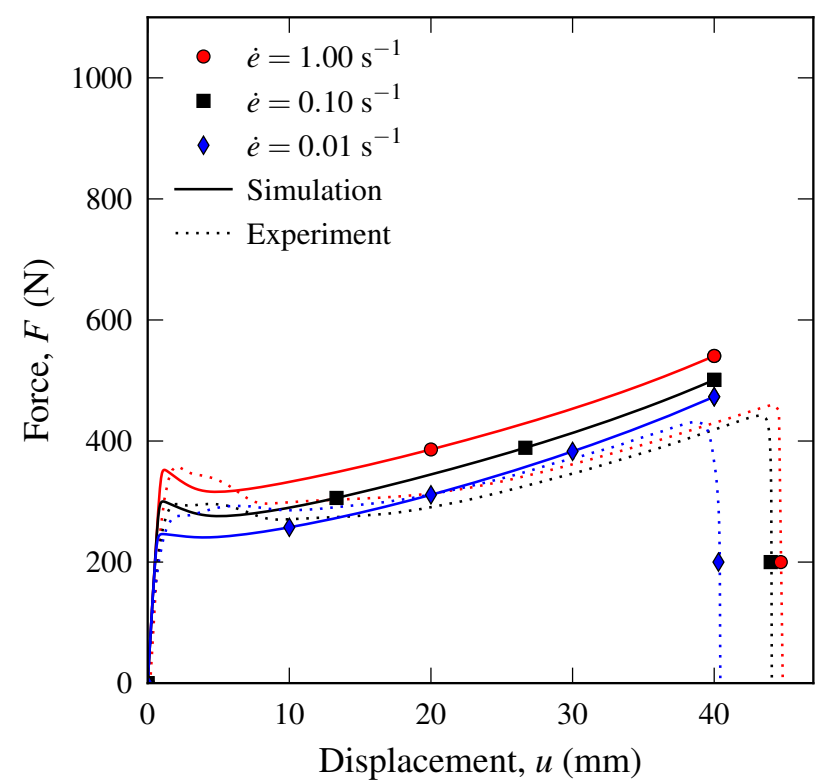

(a) $T=25^{\circ} \mathrm{C}$

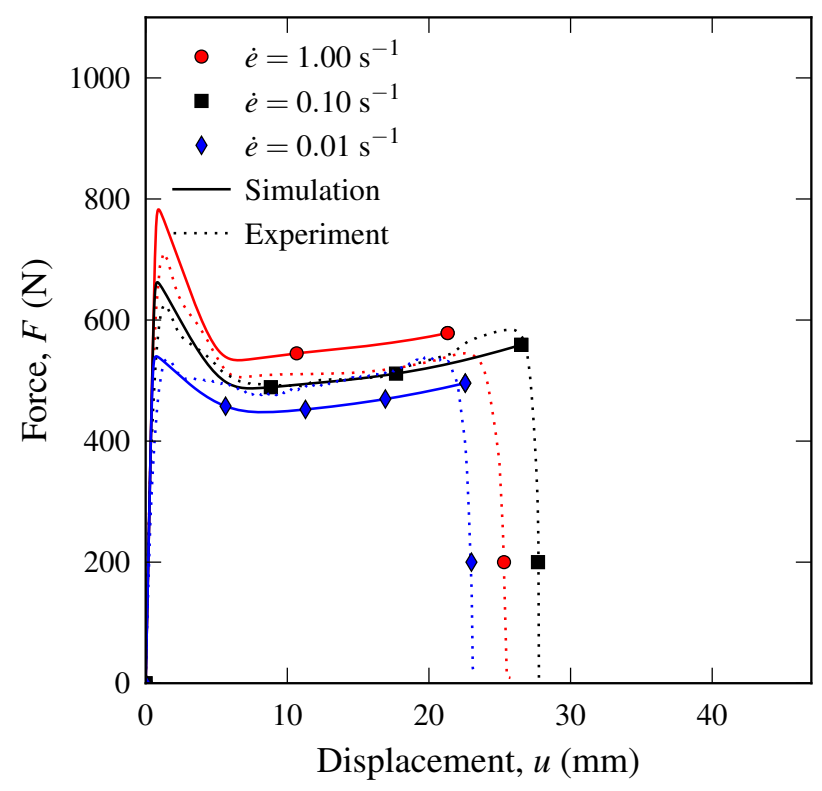

(c) $T=-15^{\circ} \mathrm{C}$

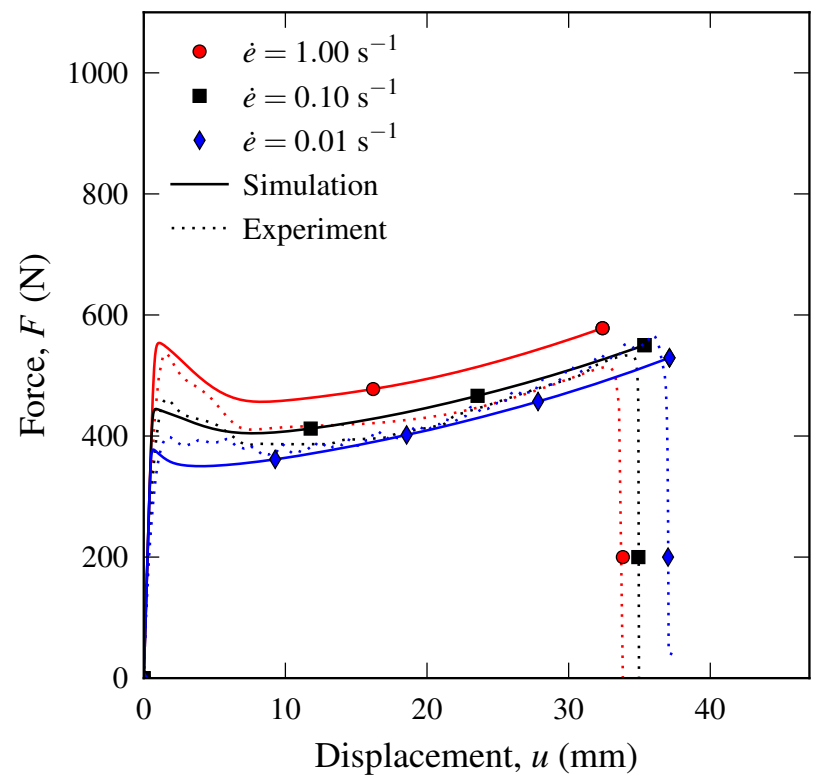

(b) $T=0{ }^{\circ} \mathrm{C}$

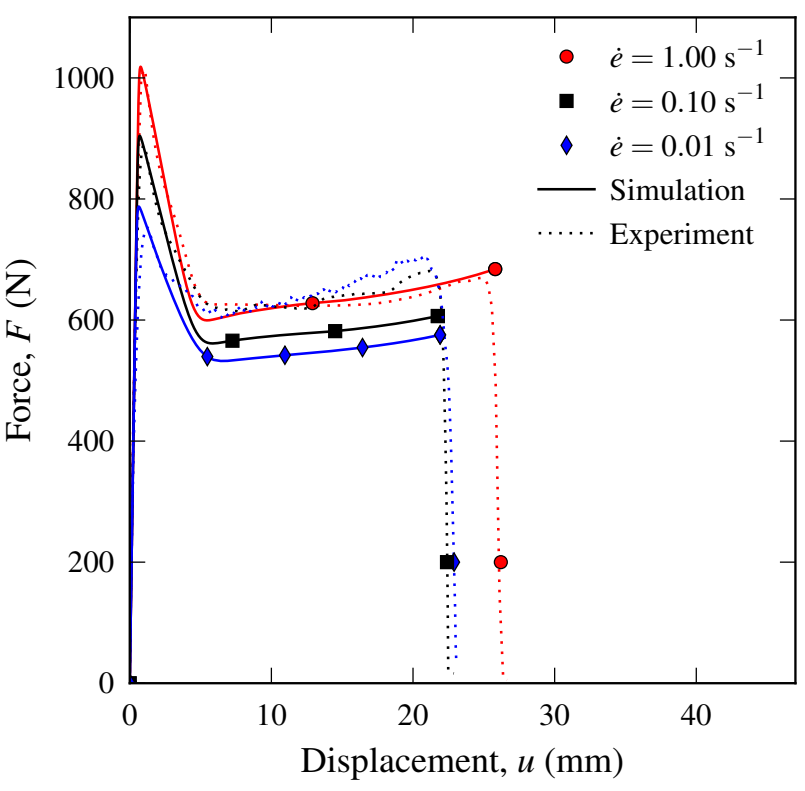

(d) $\mathrm{T}=-30^{\circ} \mathrm{C}$

Figure 12: Force vs. displacement curves from uniaxial tension tests and numerical simulations at three different nominal strain rates, $\dot{e}=0.01 \mathrm{~s}^{-1}, \dot{e}=0.1 \mathrm{~s}^{-1}$, and $\dot{e}=1.0 \mathrm{~s}^{-1}$, and at four different temperatures, (a) $T=25^{\circ} \mathrm{C}$, (b) $T=0{ }^{\circ} \mathrm{C},(\mathrm{c}) T=-15^{\circ} \mathrm{C}$ and (d) $T=-30{ }^{\circ} \mathrm{C}$.

model was extracted at the nodes where the velocity boundary condition was applied, see Figure 8

Due to the constant locking stretch, the longitudinal strain saturates at approximately the correct level 


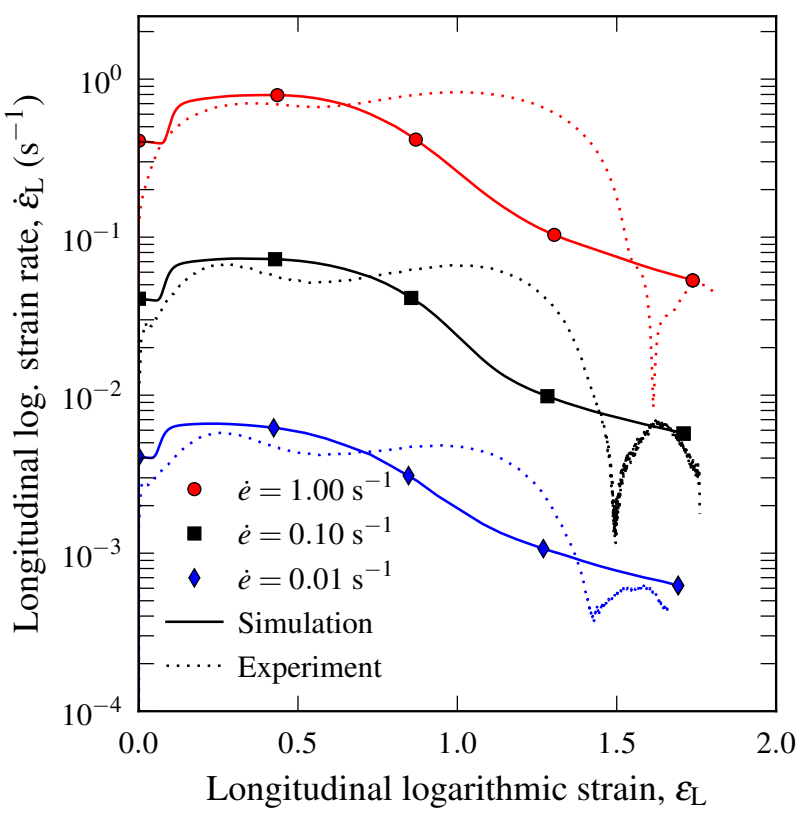

(a) $T=25^{\circ} \mathrm{C}$

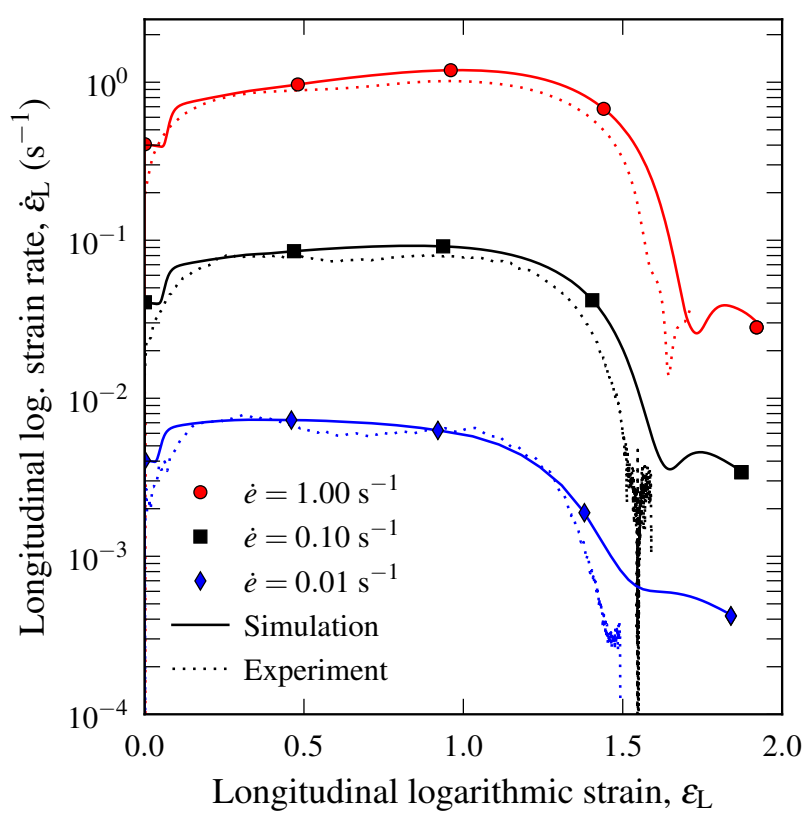

(c) $T=-15^{\circ} \mathrm{C}$

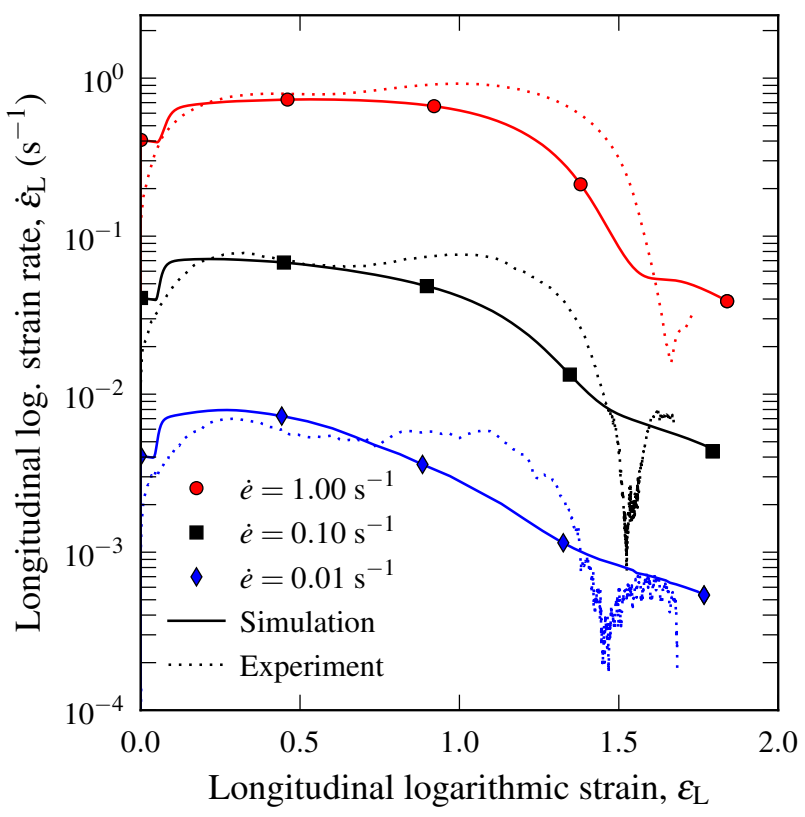

(b) $T=0{ }^{\circ} \mathrm{C}$

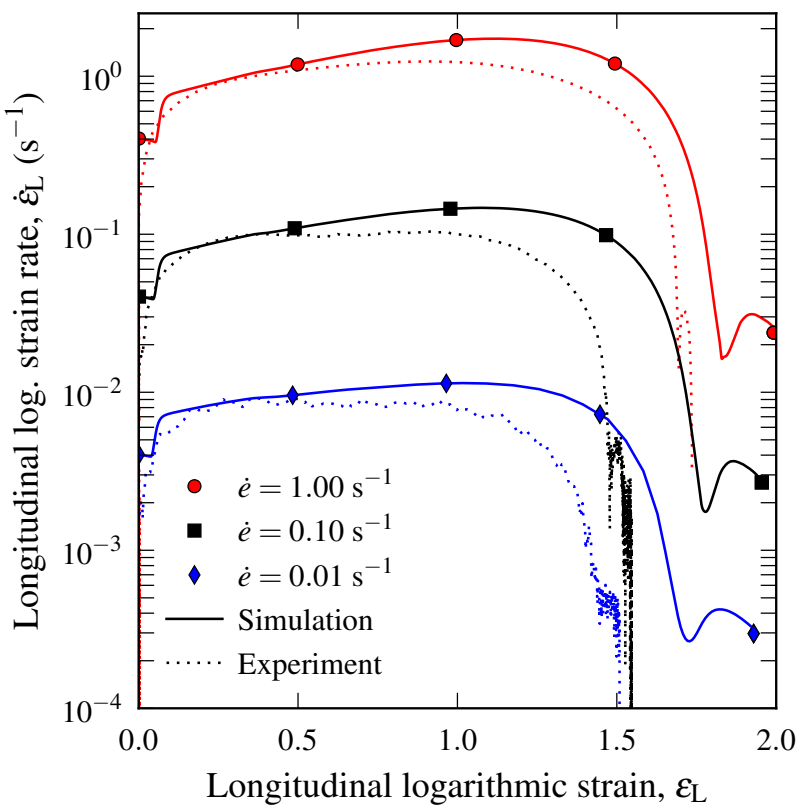

(d) $T=-30{ }^{\circ} \mathrm{C}$

Figure 13: Longitudinal logarithmic strain rate vs. longitudinal logarithmic strain from uniaxial tension tests and numerical simulations at three different nominal strain rates, $\dot{e}=0.01 \mathrm{~s}^{-1}, \dot{e}=0.1 \mathrm{~s}^{-1}$, and $\dot{e}=1.0 \mathrm{~s}^{-1}$, and at four different temperatures, (a) $T=25^{\circ} \mathrm{C}$, (b) $T=0{ }^{\circ} \mathrm{C}$, (c) $T=-15^{\circ} \mathrm{C}$ and (d) $T=-30{ }^{\circ} \mathrm{C}$. 


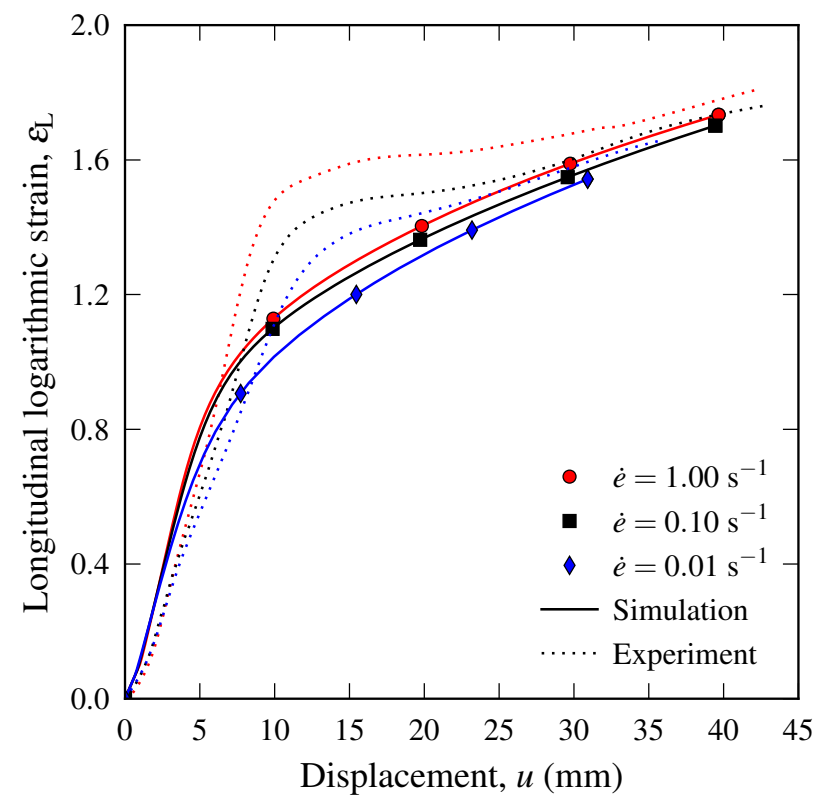

(a) $T=25^{\circ} \mathrm{C}$

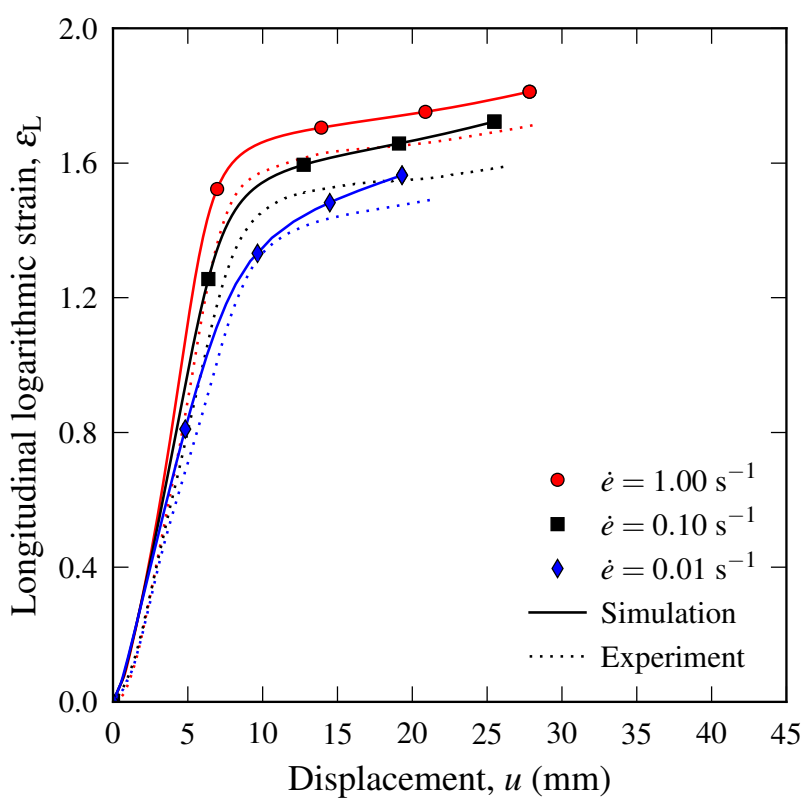

(c) $T=-15^{\circ} \mathrm{C}$

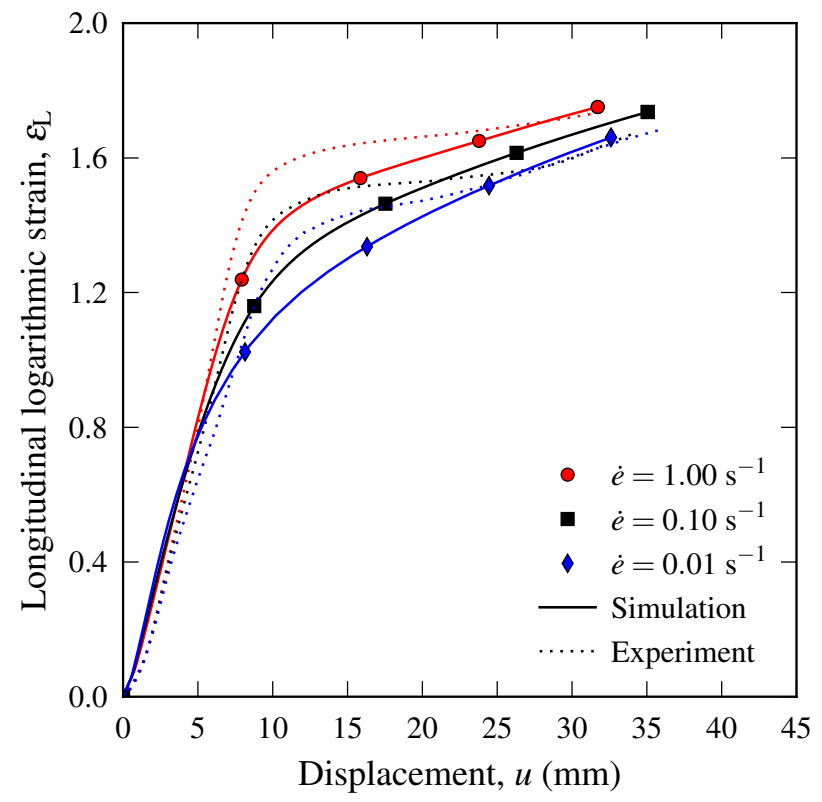

(b) $T=0{ }^{\circ} \mathrm{C}$

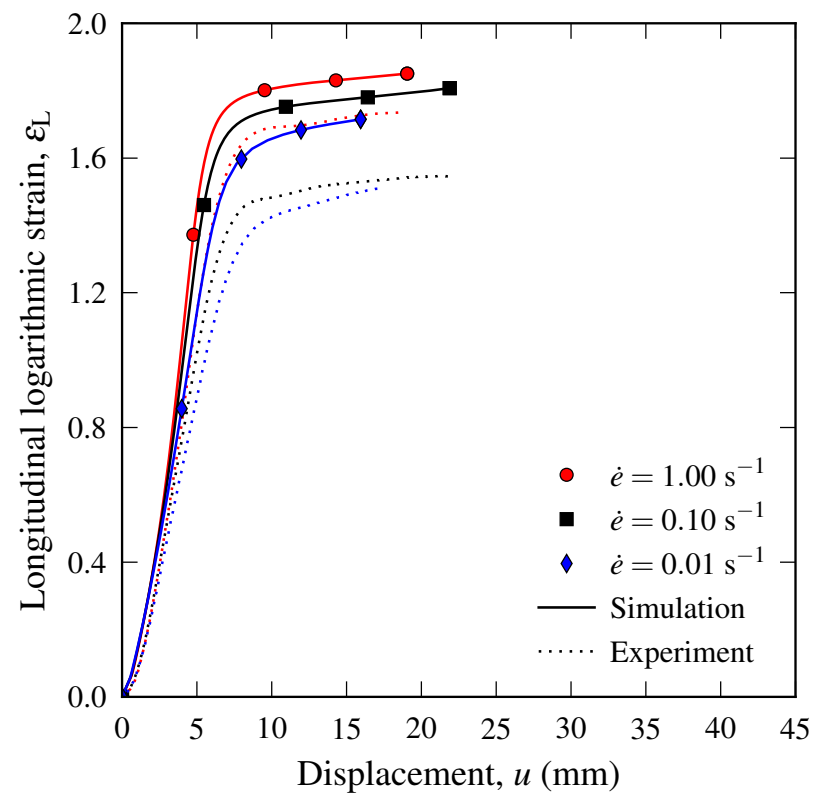

(d) $T=-30{ }^{\circ} \mathrm{C}$

Figure 14: Local longitudinal logarithmic strain vs. global displacement from uniaxial tension tests and numerical simulations at three different nominal strain rates, $\dot{e}=0.01 \mathrm{~s}^{-1}, \dot{e}=0.1 \mathrm{~s}^{-1}$, and $\dot{e}=1.0 \mathrm{~s}^{-1}$, and at four different temperatures, (a) $T=25^{\circ} \mathrm{C},(\mathrm{b})$ $T=0{ }^{\circ} \mathrm{C}$, (c) $T=-15^{\circ} \mathrm{C}$ and (d) $T=-30{ }^{\circ} \mathrm{C}$. 
for all simulations. However, as has been the case for previous simulation results, the change in the shear modulus in Part B of the model is clearly evident. At room temperature, the strain saturates more gradually, as seen in Figure 14a. As the temperature is decreased, the shear modulus in Part B is continuously reduced leading to a rather accurate prediction of the longitudinal strain as a function of global displacement at a temperature of $-15{ }^{\circ} \mathrm{C}$ (Figure $14 \mathrm{c}$ ). At a temperature of $-30{ }^{\circ} \mathrm{C}$ (Figure 14d), the shear modulus has been reduced too much, causing the longitudinal strain to saturate at a level which is too high. However, it should be noted that the global displacement measured in the experiments is not directly comparable to the displacement in the simulations. The reason for this is twofold: (1) the specimen was clamped in the testing machine which could have caused some slippage between the clamping rig and the tensile specimen, and (2) the machine stiffness could have affected the displacement recorded by the testing machine. Nevertheless, Figure 14 demonstrates the constitutive model's capability of capturing both the local and global material behaviour of the tensile specimen.

\subsection{Comparison of deformed shape}

Figure 15 shows a comparison between the deformed shape of the specimen from experiments and simulations at room temperature and a strain rate of $\dot{e}=1.0 \mathrm{~s}^{-1}$. The deformed shape of the finite element model is outlined in red on the images from the experiments. As evident from Figure 15, there are some discrepancies between simulation and experiment. At a relatively small displacement of $u=3 \mathrm{~mm}$ (Figure 15a) the agreement between simulation and experiment is excellent. However, at a displacement of $8 \mathrm{~mm}$, the simulation deviates from experiment. The specimen has not contracted enough due to the network hardening from Part B which limits the neck formation and accelerates neck propagation. All these observations can be explained from Figure $14 \mathrm{a}$ where we see that at $u=3 \mathrm{~mm}$ there is excellent agreement between simulation and experiment. After $u \approx 6 \mathrm{~mm}$ the simulation starts to deviate from the experiment due to the network hardening in Part B limiting the longitudinal strain, and a displacement of approximately $35 \mathrm{~mm}$ has to be reached before the longitudinal strain from simulation and experiment agrees again.

\section{Concluding remarks}

We have presented a thermo-elasto-viscoplastic constitutive model describing the thermomechanical behaviour of a cross-linked low density polyethylene (XLPE) at different temperatures and strain rates. The constitutive model consists of two parts: Part A represents thermoelasticity and thermoviscoplasticity, 


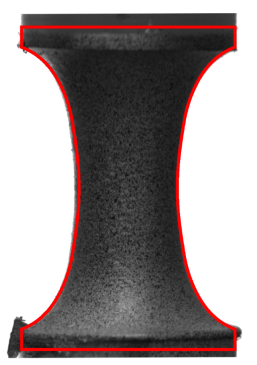

(a) $u=3 \mathrm{~mm}$

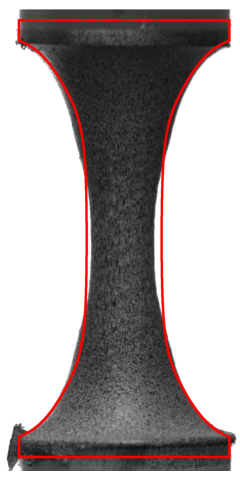

(b) $u=8 \mathrm{~mm}$

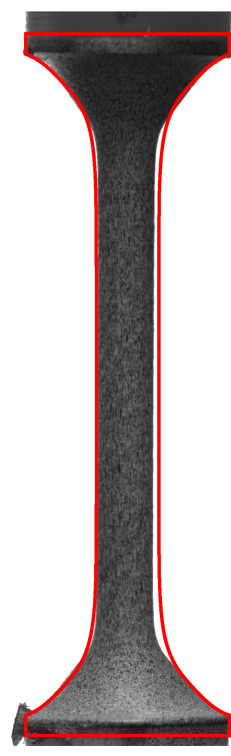

(c) $u=21 \mathrm{~mm}$

Figure 15: A comparison of the deformed shape of a specimen tested at $T=25^{\circ} \mathrm{C}$ and $\dot{e}=1.0 \mathrm{~s}^{-1}$ from finite element analysis and experiment at three magnitudes of displacement: (a) $3 \mathrm{~mm}$, (b) $8 \mathrm{~mm}$ and (c) $21 \mathrm{~mm}$. The deformed shape from the finite element analysis is outlined in red on the images from the experiment.

whereas Part B represents entropic strain hardening due to alignment of the polymer chains during deformation. Assuming that the contributions from the main $\alpha$ and the secondary $\beta$ relaxation processes are additive, Ree-Eyring dashpots were successfully used to describe yielding as a function of temperature and strain rate. In addition, the yield stress of the material was modelled as pressure insensitive, and the plastic flow was taken to be isochoric. There were two contributions to strain hardening in the model: (1) kinematic hardening from the eight chain spring in Part B, and (2) isotropic hardening introduced by the deformation dependent reference strain rates in the viscous dashpots. A phenomenological expression was proposed to describe the increase in Young's modulus as the material was cooled down. The constitutive model was implemented in a nonlinear finite element (FE) code using a semi-implicit stress update algorithm combined with sub-stepping and a numerical scheme to calculate the consistent tangent operator.

The constitutive model was calibrated from the stress-strain curves obtained in uniaxial tension tests performed at four different temperatures and three nominal strain rates, as reported in [11]. Considering the stress-strain curves, good agreement between simulations and experiments was achieved, as evident by Figure 9. For the temperature increase, qualitative agreement was obtained between numerical predictions and experimental values. The predictions by the FE model in terms of volumetric strain, force vs. global 
displacement, local strain vs. local strain rate, global displacement vs. strain and the deformed shape of the tensile specimen were in good overall agreement with the experimental counterparts, and these results serve as validation in the sense that the material model, which is calibrated from local stress-strain data, is able to predict the global response adequately.

\section{Acknowledgements}

The authors wish to thank the Research Council of Norway for funding through the Petromaks 2 Programme, Contract No.228513/E30. The financial support from ENI, Statoil, Lundin, Total, Scana Steel Stavanger, JFE Steel Corporation, Posco, Kobe Steel, SSAB, Bredero Shaw, Borealis, Trelleborg, Nexans, Aker Solutions, FMC Kongsberg Subsea, Marine Aluminium, Hydro and Sapa are also acknowledged. Special thanks is given to Nexans Norway for providing the material. The help from Associate Professor David Morin and Dr. Torodd Berstad regarding the implementation of the constitutive model is also greatly appreciated. The authors would also like to thank Professor Hans van Dommelen at Eindhoven University of Technology for his insightful comments.

\section{References}

[1] R. Haward, G. Thackray, The use of a mathematical model to describe isothermal stress-strain curves in glassy thermoplastics, Proceedings of the Royal Society of London 302 (1968) 453-472. doi:10.1098/rspa.1968.0029

[2] H. Eyring, Viscosity, Plasticity, and Diffusion as Examples of Absolute Reaction Rates, The Journal of Chemical Physics 4 (1936) 283-291. doi:10.1063/1.1749836

[3] L. R. G. Treloar, The Physics of Rubber Elasticity, 3rd Edition, Oxford University Press, Great Clarendon Street, Oxford, 1975.

[4] M. C. Boyce, D. M. Parks, A. S. Argon, Large inelastic deformation of glassy polymers. Part I: Rate dependent constitutive model, Mechanics of Materials 7 (1988) 15-33. doi:10.1016/0167-6636(88)90003-8

[5] E. M. Arruda, M. C. Boyce, A three-dimensional constitutive model for the large stretch behavior of rubber elastic materials, Journal of the Mechanics and Physics of Solids 41 (1993) 389-412. doi:10.1016/0022-5096(93)90013-6

[6] T. Ree, H. Eyring, Theory of non-Newtonian flow. I. Solid plastic system, Journal of Applied Physics 26 (1955) $793-800$. doi:10.1063/1.1722098

[7] D. J. A. Senden, S. Krop, J. A. W. van Dommelen, L. E. Govaert, Rate- and temperature-dependent strain hardening of polycarbonate, Journal of Polymer Science, Part B: Polymer Physics 50 (2012) 1680-1693. doi:10.1002/polb.23165

[8] J. L. Halary, F. Laupretre, L. Monnerie, Polymer Materials: Macroscopic Properties and Molecular Interpretations, John Wiley \& Sons Inc, Hoboken, New Jersey, 2011, Ch. 1, p. 17.

[9] E. Arruda, M. Boyce, Evolution of plastic anisotropy in amorphous polymers during finite straining, International Journal of Plasticity 9 (1993) 697-720. doi:10.1007/978-94-011-3644-0_112 
[10] J. S. Bergström, S. M. Kurtz, C. M. Rimnac, A. A. Edidin, Constitutive modeling of ultra-high molecular weight polyethylene under large-deformation and cyclic loading conditions, Biomaterials 23 (2002) 2329-2343. doi:10.1016/ S0142-9612(01)00367-2

[11] J. Johnsen, F. Grytten, O. S. Hopperstad, A. H. Clausen, Influence of strain rate and temperature on the mechanical behaviour of rubber-modified polypropylene and cross-linked polyethylene, Mechanics of Materials 114 (2017) 40-56. doi:https: //doi.org/10.1016/j.mechmat.2017.07.003

[12] M. Ponçot, F. Addiego, A. Dahoun, True intrinsic mechanical behaviour of semi-crystalline and amorphous polymers: Influences of volume deformation and cavities shape, International Journal of Plasticity 40 (2013) 126-139. doi:10.1016/j . ijplas.2012.07.007

[13] E. M. Arruda, M. C. Boyce, R. Jayachandran, Effects of strain rate, temperature and thermomechanical coupling on the finite strain deformation of glassy polymers, Mechanics of Materials 19 (1995) 193-212. doi:10.1016/0167-6636(94) 00034-E

[14] R. S. Hoy, M. O. Robbins, Strain Hardening of Polymer Glasses: Effect of Entanglement Density, Temperature, and Rate, Journal of Polymer Science, Part B: Polymer Physics 44 (2006) 3487-3500. doi : 10.1002/polb. 21012

[15] L. E. Govaert, T. A. P. Engels, M. Wendlandt, T. A. Tervoort, U. W. Suter, Does the Strain Hardening Modulus of Glassy Polymers Scale with the Flow Stress?, Journal of Polymer Science Part B: Polymer physics 46 (2008) 2475-2481. doi: 10.1002/polb.21579

[16] M. Wendlandt, T. A. Tervoort, U. W. Suter, Non-linear, rate-dependent strain-hardening behavior of polymer glasses, Polymer 46 (2005) 11786-11797. doi:10.1016/j.polymer.2005.08.079.

[17] D. J. A. Senden, J. A. W. van Dommelen, L. E. Govaert, Strain Hardening and Its Relation to Bauschinger Effects in Oriented Polymers, Journal of Polymer Science Part B: Polymer Physics 48 (2010) 1483-1494. doi:10.1002/polb.22056

[18] G. W. Adams, R. J. Farris, Latent Energy of Deformation of Bisphenol A Polycarbonate, Journal of Polymer Science Part B: Polymer Physics 26 (1988) 433-445. doi:10.1002/polb.1988.090260216.

[19] M. C. Boyce, E. L. Montagut, A. S. Argon, The effects of thermomechanical coupling on the cold drawing process of glassy polymers, Polymer Engineering \& Science 32 (1992) 1073-1085. doi:10.1002/pen.760321605

[20] S. Hillmansen, S. Hobeika, R. N. Haward, P. S. Leeversa, The Effect of Strain Rate, Temperature and Molecular Mass on the Tensile Deformation of Polyethylene, Polymer Engineering \& Science 40 (2) (2000) 481-489. doi:10.1002/pen.11180

[21] S. Hillmansen, R. N. Haward, Adiabatic failure in polyethylene, Polymer 42 (22) (2001) 9301-9312. doi:10.1016/ S0032-3861(01)00447-5

[22] J. Richeton, S. Ahzi, K. S. Vecchio, F. C. Jiang, A. Makradi, Modeling and validation of the large deformation inelastic response of amorphous polymers over a wide range of temperatures and strain rates, International Journal of Solids and Structures 44 (2007) 7938-7954. doi:10.1016/j.ijsolstr.2007.05.018

[23] D. Garcia-Gonzalez, R. Zaera, A. Arias, A hyperelastic-thermoviscoplastic constitutive model for semi-crystalline polymers: Application to PEEK under dynamic loading conditions, International Journal of Plasticity 88 (2017) 27-52. doi : 10.1016/ j.ijplas.2016.09.011

[24] M. Polanco-Loria, A. H. Clausen, T. Berstad, O. S. Hopperstad, Constitutive model for thermoplastics with structural applications, International Journal of Impact Engineering 37 (2010) 1207-1219. doi:10.1016/j.ijimpeng.2010.06.006

[25] R. Raghava, R. M. Caddell, G. S. Y. Yeh, The macroscopic yield behaviour of polymers, Journal of Materials Science 8 
(1973) 225-232. doi:10.1007/BF00550671

[26] A. S. Ognedal, A. H. Clausen, M. Polanco-Loria, A. Benallal, B. Raka, O. S. Hopperstad, Experimental and numerical study on the behaviour of PVC and HDPE in biaxial tension, Mechanics of Materials 54 (2012) 18-31. doi:10.1016/j. mechmat.2012.05.010

[27] L. Anand, N. M. Ames, V. Srivastava, S. A. Chester, A thermo-mechanically coupled theory for large deformations of amorphous polymers. Part I: Formulation, International Journal of Plasticity 25 (2009) 1474-1494. doi:10.1016/j.ijplas. 2008.11 .004

[28] N. M. Ames, V. Srivastava, S. A. Chester, L. Anand, A thermo-mechanically coupled theory for large deformations of amorphous polymers. Part II: Applications, International Journal of Plasticity 25 (2009) 1495-1539. doi:10.1016/j. ijplas.2008.11.005

[29] A. Maurel-Pantel, E. Baquet, J. Bikard, J. L. Bouvard, N. Billon, A thermo-mechanical large deformation constitutive model for polymers based on material network description: Application to a semi-crystalline polyamide 66, International Journal of Plasticity 67 (2015) 102-126. doi:10.1016/j.ijplas.2014.10.004.

[30] V. Srivastava, S. A. Chester, N. M. Ames, L. Anand, A thermo-mechanically-coupled large-deformation theory for amorphous polymers in a temperature range which spans their glass transition, International Journal of Plasticity 26 (2010) 1138-1182. doi:10.1016/j.ijplas.2010.01.004

[31] J. Johnsen, F. Grytten, O. S. Hopperstad, A. H. Clausen, Experimental set-up for determination of the large-strain tensile behaviour of polymers at low temperatures, Polymer Testing 53 (2016) 305-313. doi:10.1016/j.polymertesting. 2016.06 .011

[32] J. Richeton, S. Ahzi, K. Vecchio, F. Jiang, R. Adharapurapu, Influence of temperature and strain rate on the mechanical behavior of three amorphous polymers: Characterization and modeling of the compressive yield stress, International Journal of Solids and Structures 43 (2006) 2318-2335. doi:10.1016/j.ijsolstr.2005.06.040

[33] E. N. Brown, P. J. Rae, E. B. Orler, The influence of temperature and strain rate on the constitutive and damage responses of polychlorotrifluoroethylene (PCTFE, Kel-F 81), Polymer 47 (2006) 7506-7518. doi:10.1016/j·polymer.2006.08.032.

[34] D. A. Şerban, G. Weber, L. Marşavina, V. V. Silberschmidt, W. Hufenbach, Tensile properties of semi-crystalline thermoplastic polymers: Effects of temperature and strain rates, Polymer Testing 32 (2013) 413-425. doi:10.1016/j. polymertesting.2012.12.002

[35] C. Bauwens-Crowet, The compression yield behaviour of polymethyl methacrylate over a wide range of temperatures and strain-rates, Journal of Materials Science 8 (1973) 968-979. doi:10.1007/BF00756628

[36] F. J. Zerilli, R. W. Armstrong, Application of Eyring's thermal activation theory to constitutive equations for polymers, in: AIP Conference Proceedings, Vol. 505, AIP, 2000, pp. 531-534. doi:10.1063/1.1303530.

[37] C. Miehe, Numerical computation of algorithmic (consistent) tangent moduli in large-strain computational inelasticity, Computer Methods in Applied Mechanics and Engineering 134 (1996) 223-240. doi:10.1016/0045-7825(96) 01019-5

[38] W. Sun, E. L. Chaikof, M. E. Levenston, Numerical approximation of tangent moduli for finite element implementations of nonlinear hyperelastic material models., Journal of Biomechanical Engineering 130 (2008) 061003-1-061003-7. doi: $10.1115 / 1.2979872$

[39] Borlink LS4201S, http://www.borealisgroup.com/en/polyolefins/products/Borlink/Borlink-LS4201S/. accessed:2016-1116 
[40] E. H. Lee, Elastic-Plastic Deformation at Finite Strains, Journal of Applied Mechanics 36 (1969) 1. doi:10.1115/1. 3564580

[41] E. de Souza Neto, D. Perić, D. Owen, Computational Methods for Plasticity: Theory and Applications, John Wiley \& Sons, Ltd., Chichester, West Sussex, 2008.

[42] G. A. Holzapfel, Nonlinear Solid Mechanics, John Wiley \& Sons, Ltd., Chichester, West Sussex, 2000.

[43] M. Boyce, G. Weber, D. Parks, On the kinematics of finite strain plasticity, Journal of the Mechanics and Physics of Solids 37 (5) (1989) 647-665. doi:10.1016/0022-5096(89)90033-1.

[44] C. Miehe, Entropic thermoelasticity at finite strains. Aspects of the formulation and numerical implementation, Computer Methods in Applied Mechanics and Engineering 120 (1995) 243-269. doi:10.1016/0045-7825(94)00057-T

[45] R. Jedynak, Approximation of the inverse Langevin function revisited, Rheologica Acta 54 (2015) 29-39. doi:10.1007/ s00397-014-0802-2

[46] L. Anand, A constitutive model for compressible elastomeric solids, Computational Mechanics 18 (1996) 339-355. doi: $10.1007 / \mathrm{BF} 00376130$

[47] Dassault Systèmes, Providence Road, Rhode Island, ABAQUS 6.14 Documentation (2014).

[48] M. Andersen, An experimental and numerical study of thermoplastics at large deformations, Ph.D. thesis, Norwegian University of Science and Technology, NTNU (2016).

[49] ISO22007-4:2008, Plastics - Determination of thermal conductivity and thermal diffusivity - Part 4: Laser flash method, 2008. 